\title{
Temperature Dependent Viral Tropism (TDVT): understanding viral seasonality and pathogenicity as applied to the avoidance and treatment of endemic viral respiratory illnesses
}

By Patrick D. Shaw Stewart and Julia Bach§

Douglas Instruments Ltd., East Garston, Hungerford, Berkshire, RG17 7HD, UK. §Amgen Inc., Thousand Oaks, California, USA.

\section{Summary}

This review seeks to explain four features of viral respiratory illnesses that have perplexed generations of virologists: (1) the seasonal timing of respiratory illness; (2) the common viruses causing respiratory illness worldwide, including year-round disease in the Tropics; (3) the rapid response of outbreaks to weather, specifically temperature; (4) the rapid arrival and termination of epidemics caused by influenza and other viruses. The inadequacy of the popular explanations of seasonality is discussed, and a simple hypothesis is proposed, called Temperature Dependent Viral Tropism (TDVT), that is compatible with the above features of respiratory illness. TDVT notes that viruses can transmit themselves more effectively if they moderate their pathogenicity (thereby maintaining host mobility) and suggests that endemic respiratory viruses accomplish this by developing thermal sensitivity within a range that supports organ-specific viral tropism within the human body, whereby they replicate most rapidly at temperatures below body temperature. This allows them to confine themselves to the upper respiratory tract and to avoid infecting the lungs, heart, gut etc. Biochemical and tissue-culture studies show that "wild" respiratory viruses show such natural thermal sensitivity. The typical early autumn surge of colds and the existence of respiratory illness in the Tropics year-round at intermediate levels are explained by the tendency for strains to adapt their thermal sensitivity to their local climate and season. The TDVT hypothesis has important practical implications for preventing and treating respiratory illness including Covid-19. TVDT is testable with many options for experiments to increase our understanding of viral seasonality and pathogenicity.

Keywords: viral respiratory illness, seasonality, pathogenicity, temperature sensitivity, Covid-19, SARS-CoV-2, influenza.

\section{Definition of terms}

In this review, "dormant" means biochemically inactive, or active at low levels. It may imply no viral replication, or low levels of replication. As discussed below, dormant virions may be invisible to the host immune system. (The word "latent" is avoided because this term can refer to viruses that integrate their genomes into the host genome, which are not considered here.) The locations of dormant viruses in the respiratory tract (in, on or between cells) is unknown, and may vary.

A "mild", "attenuated" or "less pathogenic" virus is one that is more thermally sensitive (ts). Such viruses possess biochemistry that is most active at temperatures below normal body temperature. A "virulent" or "highly pathogenic" virus is one that is less ts, possessing biochemistry that is active at both body temperature and lower temperatures. A highly pathogenic virus is likely to cause respiratory illness at any ambient temperature. A mild respiratory virus is likely to cause respiratory illness only at low ambient temperature. For a mild respiratory virus, the "permissive" temperature 
is the temperature of the nose and throat, while the temperature of the lungs is "restrictive". For a highly pathogenic virus the temperature of all parts of the body is permissive.

\section{Introduction: conventional explanations of the seasonality of viral illness, and their problems}

Scientists have for decades recognized the tendency of viral illnesses to worsen during predictable seasons $[1,2]$. This review focuses on four features of respiratory viral illness seasonality that lack rigorous and convincing scientific explanations:
A. Seasonal timing
B. Common viruses worldwide
C. Weather influence
D. Rapid arrival and termination

\section{A. Seasonal Timing}

First, the seasonal occurrence of viral respiratory illness in temperate regions, with more illness during the colder seasons (Figure 1), including a surge in respiratory illness that frequently appears in the early autumn (Figure 2), demands scientific explanation. The shared winter seasonality of so many completely unrelated viral species is extraordinary $[3,4]$. The diverse characteristics of some important human respiratory viruses that cause illness with winter seasonality are shown in Table 1.

The most popular explanations of the winter seasonality of respiratory viruses fall into three categories, designated as follows ${ }^{1}$ : E1, increased crowding of human hosts in winter encourages the spread of respiratory viruses; $E 2$, ambient conditions allow respiratory viruses to survive outside the body longer in cold and dry conditions; E3, the immune defenses of human hosts are weaker during the winter months. This review suggests that these explanations are important, but not the main drivers of epidemic timing.

Crowding (E1) would predict that summer sporting events and festivals would be associated with increased transmission of respiratory viruses, which is not the case. Tamerius et al. showed this lack of association for influenza [2]. Figure 3 shows that "Google flu search" did not increase in any country (for which it was recorded) in the Northern Hemisphere during the FIFA 2014 World Cup ${ }^{2}$, despite spectators and fans packing into crowded stadiums, bars, restaurants and homes in order to view World Cup matches. School holidays are also not well-correlated with respiratory illness. For example, children are on holiday in Singapore in December, but this coincides with the yearly peak of influenza [2]. The crowding hypothesis E1 would also predict that colds and flu would be much more prevalent in large cities than in the countryside, which is not the case [5].

Survival (E2) focuses on the suggestion that cold and dry conditions increase the survival of the virus outside the body, thereby encouraging transmission. E2 predicts that colds and flu would be reduced during wet or humid weather. A recent review of Covid-19 data subscribes to this explanation, but mostly focuses on absolute temperature and humidity, not weather changes, and concludes that much of the data is confounded with public policies implemented in the reaction to the pandemic [6]. Lidwell et al. and Hajat et al. [3, 7]

\footnotetext{
${ }^{1}$ Note that these explanations were designated M1, M2 and M3 in the 2016 review by Shaw Stewart. The designations have been changed to E1, E2 and E3 because the previous designations confused some readers. M4 becomes TDVT in this review.

${ }^{2}$ Google flu search. Retrieved August 2015. Google Flu Trends was a web service operated by Google that attempted to make predictions about influenza activity. After Google ceased publishing Flu Trends in August 2015, the graphical data for related searches was still available as "Google flu search".
} 
found that there was no meaningful correlation between upper and lower respiratory tract illness in the UK, and humidity (or rainfall) or cloud cover, in the absence of a parallel temperature correlation. (In many cases, humidity is correlated with higher or lower levels of colds and flu, but absolute and relative humidity are themselves highly correlated with temperature, and these relationships seem to be driven by temperature, not humidity [7]). In tropical locations that have rainy seasons, colds and flu arrive during those seasons, which is the opposite trend to the popular explanation. Also, some respiratory viruses such as rhinovirus and adenovirus survive better in humid conditions (Table 3), yet they are seasonal in the often cold, dry air of winter, with virtually all other viral respiratory illnesses. Lastly, a recent study found that influenza viruses supplemented with material from the apical surface of human airway epithelial cells remained infectious irrespective of relative humidity, suggesting that humidity is not an important factor in the winter seasonality of influenza [8].

The immune defenses (E3) explanation assumes that the immune system simply does not function as well in the significantly colder temperatures that must be endured during the winter in temperate regions. However, Paynter et al. found that vaccines were slightly more effective in winter than in summer [4]. An early study on an isolated tropical island found that colds increased in September when the temperature dropped by only $1-2^{\circ} \mathrm{C}$, from around $24^{\circ} \mathrm{C}$ at night to around $22^{\circ} \mathrm{C}$ [9]. It seems implausible that such a small temperature drop, starting at a relatively high temperature, could meaningfully depress human immune defenses. Experimental studies by Andrewes, Dowling and Douglas [10-12] suggest that human immune defenses are not made meaningfully weaker by experimental chilling of individuals (although these studies used "pedigree" viral strains that may behave differently from wild type strains; see Premise \#4 below).

Others propose that the winter seasonality of Covid-19 and other viral illnesses is driven by vitamin $D$ deficiency due to reduced sunlight during the winter months. There are several problems here: (1) vitamin D levels typically peak in September in temperate locations (Figure 4) [13], which is when the autumn surge of respiratory illness often arrives (Figure 2). (2) Vitamin D levels change slowly, typically over a few months (Figure 4), whereas respiratory illness often follows temperature drops within one or two weeks (Figure 5). (3) Colds and flu do not follow overcast weather, and they do not decrease after sunny weather [7]. We conclude that vitamin D or other deficiencies brought on by a lack of sunshine may contribute to the prevalence of colds and flu in late winter and early spring, but they are unlikely to be the main drivers of winter seasonality $[14,15]^{3}$.

\section{B. Common viruses worldwide}

Second, respiratory illnesses occur year-round in the Tropics, caused by a set of viruses that are very similar to those that cause seasonal illness in temperate regions, despite profound differences in climate. Table 2 lists the viruses that most frequently caused hospitalization of children in three studies based at hospitals at different latitudes. There are striking similarities. Moreover, viral respiratory illnesses are rare in mid-summer in temperate regions, but they usually occur throughout the year at moderate levels in the Tropics (sometimes with a surge in the rainy season). For example, Figure 6 shows that influenza is almost absent during the summer in Northern USA and Sydney (Australia), but it is present year-round in Singapore and during the rainy season in Fortaleza

\footnotetext{
${ }^{3}$ Epidemiological studies show that vitamin D deficiency is associated with increased incidence of cancer and cardiovascular disease, but a very large, randomized, placebo-controlled trial of supplementation with vitamin $D$ (cholecalciferol) did not result in a lower incidence of either disease. It has been suggested that other important effects of sunshine such as the photorelease of nitric oxides in the skin may explain the link with reduced cardiovascular disease and similar considerations may apply to lower cancer incidence.
} 
(Brazil). The same trends can be seen in the hospitalization of children caused by respiratory illnesses [16-18] and also in the prevalence of influenza reported by the World Health Organization for the period 1964-75, a time when most people living in the Tropics did not have air-conditioning [19].

\section{Weather influence}

Third, there is a rapid response of illness to regional weather patterns, where epidemics of colds and flu often follow one or two weeks after a cold-weather spell. These illnesses typically follow drops in temperature $[3,7,20]$ too rapidly to be due to changes in transmission (see Figure 5). The SARSCoV-2 pandemic is an emerging situation, and some have cautioned against assuming that this virus will follow the same seasonal patterns of other viruses [21], while others point out that studies of environmental influences on Covid-19 have yielded confusing and contradictory results [22]. In the case of Covid-19, outbreaks in many areas have followed regional patterns. For the United States, the autumn 2020 wave of Covid-19 began in the Midwestern states [23, 24]. This area of the United States experienced two severe, record-breaking cold snaps in September and October 2020 [25]. SARS-CoV-2 data will continue to stream in, but it (already) appears to be affected by weather.

\section{Rapid arrival and termination}

Fourth, as characterized by Hope-Simpson, an "explosive" arrival and rapid termination is observed for many epidemics of influenza and other endemic respiratory viruses (Figure 7). Influenza frequently arrives simultaneously throughout large geographical areas, in isolated remote rural settings and nearby towns and cities, and even widely-separated locations at similar latitudes [5, 19]. Figure 8 shows that during the Spanish Influenza epidemic of 1918/19 most European countries experienced a single peak of mortality during a two-month window (October and November 1918), with winter mortality returning to normal levels in all but four countries in 1920 [26]. For SARS-CoV2 , cases have rapidly decreased at unexpected times during the pandemic $[27,28]$. For example, WHO reported that in the last week of January 2021 Covid-19 cases declined in five of six WHO regions (the exception being the tropical South-East Asia region) in spite of a lack of widespread immunity and very limited vaccination [29].

This review offers a novel explanation for the seasonal characteristics of viral respiratory illnesses, based on the idea that viral strains maximize their transmission and rapidly adapt to climate and weather conditions, influencing their pathogenicity.

\section{The four premises of Temperature Dependent Viral Tropism (TDVT)}

The Temperature Dependent Viral Tropism (TDVT) hypothesis and research program explains the four features of seasonal respiratory outbreaks as listed above. The hypothesis is built on four simple premises:

1. Very pathogenic viruses usually reduce the mobility of their hosts. In well-established endemic viruses, mild or moderately virulent strains are selected because they are more likely to be transmitted to new hosts than more pathogenic ones.

2. In the case of respiratory viruses, most moderate their pathogenicity by having one or more ts steps in their lifecycle (Figure 9A), such that they replicate best below normal body temperature. Less $t s$ strains are more likely to invade the lungs and internal organs, and are therefore more virulent.

3. This thermal sensitivity allows most respiratory viruses to confine themselves to the nose and throat, where they can cause coughing, sneezing and runny noses, all of which can help to transmit them to other hosts.

4. If ambient temperature remains stable, or rises, $t s$ respiratory viruses often remain dormant in the respiratory tracts of their hosts. If ambient temperature drops or hosts are chilled they are likely to become active and may cause respiratory illness. 
Based on these premises, this review concludes that the seasonality of viral outbreaks is mainly a consequence of viral thermal sensitivity. Natural selection causes the level of thermal sensitivity to adapt to local conditions. Thermal sensitivity therefore varies with the seasons and in different climates. Note that most biological processes are "temperature-sensitive" in that they proceed more rapidly at higher temperatures. Our hypothesis proposes that the thermal sensitivity of respiratory viruses is unusual because it acts in the opposite direction: such viruses are suggested to be less active at higher temperatures.

The Nobel laureate André Lwoff suggested part of the hypothesis in 1959, when he noted that the degree of virulence of viruses is often related to their level of thermal sensitivity. In 1979 Richman and Murphy developed this further, discussing many examples of thermal sensitivity in natural and lab-made viral strains, and noting that the near-universal attenuation of $t s$ strains made them good candidates for vaccines [30]. The full hypothesis was proposed by Shaw Stewart and discussed at length in 2016, focusing on seasonality and the natural selection of strains with varying degrees of thermal sensitivity and pathogenicity [31]. The same hypothesis was put forward by Eccles in 2020, this time concentrating on the advantages of thermal sensitivity to the virus [32]. This shorter review summarizes the evidence for the hypothesis, including some recent studies, and discusses its implications for avoiding and treating respiratory illness including Covid-19.

\section{Premise \#1: mild or moderately pathogenic endemic viral strains are more likely to be transmitted}

Viral infections that humans occasionally pick up from other animals, normally vertebrates, may cause mild flu-like symptoms but they may also be highly pathogenic. For example, at least five unrelated groups of RNA viruses have been identified as the causes of human hemorrhagic fevers. These are illnesses that cause internal or external bleeding and are often fatal. Examples include Whitewater Arroyo virus fever, Rift Valley fever, Lujo virus, as well as Argentine, Bolivian, Brazilian, Chapare, Venezuelan, Hantavirus, Crimean-Congo, Omsk, Bas-Congo, and Kyasanur Forest hemorrhagic fevers. The hemorrhagic fevers caused by Marburg virus, Lassa fever virus and Ebola virus have been seen to spread between human hosts [33]. Other viruses that "spilled over" to humans from other species and caused epidemics with high mortality include Spanish influenza, HIV, SARS-CoV-1, MERS and SARS-CoV-2. Clearly these viruses are not yet well-adapted to their hosts, yet they are much more pathogenic than most well-established endemic viruses such as cold viruses, supporting the proposal that selective pressures have resulted in a loss of virulence as viruses adapt to their hosts and become endemic.

The moderation of viral pathogenicity is predicted by the well-known "transmission-virulence tradeoff" hypothesis [34]. This states that the benefits of increased replication (and the subsequent increased shedding of virions) must be balanced against the reduction of time during which shedding takes place, and the reduced mobility of hosts. The trade-off hypothesis was introduced to explain patterns in myxomatosis data [34]. Myxomatosis has been studied intensely because it provides a classic reference for the rapid evolution of virulence. It is a highly pathogenic viral disease, normally spread by mosquitos, that jumped from New World rabbits to European rabbits. During the first year after its introduction to Australia, it is estimated to have killed $99.5 \%$ of the rabbits that it infected [35]. Clearly, though, even this high rate allowed around $0.5 \%$ to recover and breed and within "a few years" the genetic resistance to the disease was seen to increase in an area where there were annual severe outbreaks of the disease. However, independent testing with laboratory rabbits showed that milder viral strains emerged on a shorter time scale. For example, a virulent (grade I) strain was introduced to rabbits at Lake Urana in 1952, causing an outbreak with a casemortality rate of over 99.5\% [35]. Eleven months after the first outbreak ended, a new outbreak occurred that was caused entirely by attenuated strains of grade III severity. It was suggested that the over-all trend towards moderate virulence (grade III) can be explained by the selective advantage for mosquito transmission of strains which cause extensive and long-persisting infectious 
skin lesions in rabbits [35]. Interestingly, when very mild strains (grade IV) were introduced in other locations they often evolved increased virulence, and grade III strains were later recovered. Similar selective trends can act on respiratory viruses, such that strains with intermediate pathogenicity become established.

There is other evidence for the moderation of virulence in viral infections. If natural selection tends to reduce the severity of the most pathogenic illnesses such that the period of transmission can increase, there should be differences between illnesses that are transmitted by insects (or other vectors) compared to those that are transmitted by direct contact. This is because transmission via vectors can take place whether or not the host is immobilized, whereas direct contact between individuals will be reduced by immobilization. Ewald, who introduced an early version of the tradeoff hypothesis in 1983, showed that pathogens that are transmitted without vectors are significantly more likely to cause illnesses that have mortality below $1 \%$ than those transmitted by vectors $(\mathrm{P}<$ 0.0005 ) [36]. (Since the trade-off model of parasite virulence was introduced to explain observations of myxomatosis, which is vector-borne, it often focuses on increased host mortality. Note, however, that in many human and animal diseases, including Covid-19, reduced mobility is likely to have greater impact than increased mortality because even in a severe epidemic, most deaths occur well after the period when transmission is most likely. Note also that more virulent pathogens may be strongly selected in settings such as hospitals and care homes [37], where transmission can take place even when individuals are very sick if adequate protective measures are not taken.)

\section{Premise \#2: most respiratory viruses are ts. Less ts strains are more virulent, and vice versa.}

Despite practical difficulties in carrying out experiments, and a lack of awareness of the natural thermal sensitivity of many respiratory viruses among virologists, viral thermal sensitivity (i.e. viruses replicating faster at lower temperatures than at body temperature) has been seen in the wet lab on many occasions. However, if selective pressure is applied and more mutations occur, thermal sensitivity can also be lost or regained in the lab and in animal hosts.

It is often easier to propagate respiratory viruses that are freshly collected from patients by incubation at temperatures below $37^{\circ} \mathrm{C}$. Rhinoviruses were first isolated at $35^{\circ} \mathrm{C}$ but a greater variety of rhinoviruses was discovered at $33^{\circ} \mathrm{C}$ [38]. Coronaviruses were first isolated at $33^{\circ} \mathrm{C}$ [39]. In 1962 Stern and Tippett [40] found that four viral specimens from patients with H2N2 "Asian" influenza grew in eggs at $33^{\circ} \mathrm{C}$ but not at $37^{\circ} \mathrm{C}$. They also grew in monkey cells at $33^{\circ} \mathrm{C}$ but more slowly or not at all at $37^{\circ} \mathrm{C}$. The authors also found (in 1962) that the well-known FM1 (H1N1, 1947) and PR8 (oldstyle HON1, 1934) strains both grew more slowly in monkey cells at $37^{\circ} \mathrm{C}$ than at $33^{\circ} \mathrm{C}$. In 1977 , Kung et al. found that nine of ten isolates of the newly emerged "Russian" H1N1 influenza were ts [41]. Oxford et al. found that 17 of 26 recent $\mathrm{H} 1 \mathrm{~N} 1$ isolates, and 2 of 11 recent $\mathrm{H} 3 \mathrm{~N} 2$ isolates were ts, giving at least 10 times more viral plaques after incubation at $34^{\circ} \mathrm{C}$ compared to $38.5^{\circ} \mathrm{C}$ [42]. Jardon and Garnier found a 3 -fold increase in recombinant adenovirus yield in HEK293S cells at $35^{\circ} \mathrm{C}$ compared to $37^{\circ} \mathrm{C}$ [43]. Sato et al. recommended $34^{\circ} \mathrm{C}$ to grow parainfluenza virus in a melanoma cell-line, MNT-1 [44]. A more recent study by the same authors, and others, found that the same cell-line was suitable for the growth of human metapneumovirus, and they recommended $33^{\circ} \mathrm{C}$ for this purpose [45].

This thermal sensitivity is readily explained by the observation that particular steps in the lifecycles of respiratory viruses are ts. Russell saw an "unexpected result" when he measured the uptake of the triple reassortant influenza virus A/Jap/Bel into cells [46]: $100 \%$ of the virus entered cells at $30^{\circ} \mathrm{C}$, compared to $50 \%$ at $38^{\circ} \mathrm{C}$ (Figure 10). Takashita et al. found roughly twice the amount of the hemagglutinin-esterase-fusion protein (HEF) of influenza $\mathrm{C}$ on the cell surface at $33^{\circ} \mathrm{C}$ compared to $37^{\circ} \mathrm{C}$, and membrane fusion mediated by HEF was observed at $33^{\circ} \mathrm{C}$ but not at $37^{\circ} \mathrm{C}$ [47]. This was due to instability of the trimeric form of HEF at $37^{\circ} \mathrm{C}$. Plotch and Krug [48] reported that the greatest 
activity of the RNA polymerase of WSN virus was at $30-32^{\circ} \mathrm{C}$. This is similar to the optimum temperature of the polymerase of influenza $\mathrm{C}$, which is $33^{\circ} \mathrm{C}[49,50]$. Ulmanen et al. [51] found that the rate of transcription by detergent-treated influenza $A$ viruses was about 10 times greater at $33^{\circ} \mathrm{C}$ than at $39.5^{\circ} \mathrm{C}$, and that the binding of a cleaved primer cap to the viral cores was "unexpectedly" much weaker at $39.5^{\circ} \mathrm{C}$ than at $33^{\circ} \mathrm{C}$. Scholtissek and Rott [52] showed that the optimum for the polymerase of the Rostock strain of fowl plague virus was five degrees below chickens' normal body temperature $\left(41^{\circ} \mathrm{C}\right)$. Gale suggests that higher temperatures are detrimental to virus binding in many cases, but that these obstacles can sometimes be overcome in the case of virulent viruses, such as HIV [53].

Virologists tend to focus on mutations that change the sequences of viral proteins. However, RNA secondary structure is inherently $t$, and conserved RNA structures (such as, in SARS-CoV-2, the s2m structure, the 3' UTR pseudoknot, and the coronavirus packaging signal) may comprise "RNA thermometers" [54] and so contribute to the evident thermal sensitivity of such viruses. Several reports showed that temperature affects the balance between transcription and viral replication. Kashiwagi et al. [55] found that, for five varied influenza A strains, genomic RNA (vRNA) unexpectedly decreased when the temperature was increased from $37^{\circ} \mathrm{C}$ to $42^{\circ} \mathrm{C}$. The PA subunit of the viral polymerase caused this thermal sensitivity. Dalton et al. suggested that the "switch" that regulates the transition from transcription to replication is dependent on temperature. They showed that the production of messenger RNA (mRNA) by the PR8 influenza strain is favored at a higher temperature $\left(41^{\circ} \mathrm{C}\right)$, with very little vRNA being produced at that temperature [56]. A plasmid-based recombinant system used by the same authors showed that as the incubation temperature increased from $31^{\circ} \mathrm{C}$ to $39^{\circ} \mathrm{C}$ the amount of replicative RNA products (cRNA and VRNA) decreased and a greater accumulation of mRNA was observed. The cRNA formed a complex with the polymerase that was particularly heat labile. We suggest that apparently "silent" mutations that affect RNA secondary structure have profound effects on the pathogenicity of respiratory viruses [57] including SARS-CoV-2.

As important as thermal sensitivity is in "wild" viruses, viral strains can adapt to higher temperatures and lose thermal sensitivity if the right selective pressure is applied in the laboratory. Most laboratory strains of respiratory viruses are propagated in cell cultures at around $37^{\circ} \mathrm{C}$, which may result in the rapid loss of ts characters, especially since viruses often mutate very rapidly when they are introduced to new hosts. For example, a $21^{\text {st }}$ century study, which looked specifically at the effect of temperature on the replication in mammalian cells of H1N1, H1N2 and H3N2 influenza A viruses isolated from pigs and birds, found that only 3 of 7 strains examined consistently replicated faster at $37^{\circ} \mathrm{C}$ than $40^{\circ} \mathrm{C}$ [58]. Note, however, that (1) the viral strains studied had been sampled up to 23 years before the publication, and propagated in eggs and cell cultures at unknown temperatures in the meantime; and, (2) all strains were "amplified" at $36-37^{\circ} \mathrm{C}$ in embryonated chicken eggs for up to four days, prior to examining thermal sensitivity. This procedure might well have selected mutated sub-strains that lacked thermal sensitivity.

This has in fact been seen in earlier studies - the ts character of strains was lost in conditions that allowed rapid replication. Chu et al. passaged a naturally-occurring ts subclone of the influenza $A$ H3N2 strain Ningxia/11/72 [59] three times through chicken embryos at a low temperature $\left(33^{\circ} \mathrm{C}\right)$, and were surprised to find that a non-ts strain "turned up". Similarly, Oxford et al. [42] found that when a naturally-occurring ts virus, A/Eng/116/78 (H1N1), was passaged five times through chicken eggs at $33^{\circ} \mathrm{C}$ it progressively lost its ts character. Both groups concluded that even at the permissive temperature $\left(33^{\circ} \mathrm{C}\right)$ the ts phenotype may confer a selective disadvantage in eggs because eggs allow rapid replication of influenza virions.

The ts character of strains may be lost in conditions that allow rapid replication, as noted above. However, the converse trend has also been seen: conditions that favor the replication of milder strains have produced ts strains. In an interesting review from 1975 [60], Preble and Youngner noted that $t s$ strains often appear spontaneously in persistent infections of cell cultures with a 
variety of unrelated insect-transmitted and respiratory viruses, including Newcastle disease virus, Western equine encephalitis virus, Sendai virus, measles virus, vesicular stomatitis virus, and Sindbis virus. Persistent infections of cell-cultures with mumps virus and vesicular stomatitis virus were also frequently established by $t s$ virus. Three more recent reports described the establishment of persistent infections of cell cultures by spontaneously-generated ts strains of influenza A [61-63]. Preble and Youngner pointed out that a balance between viral and cell replication is required to establish persistent infections and that since $t s$ strains tend to be less virulent they may allow such infections to become established [60]. They suggested that similar mechanisms may be involved in the establishment of persistent infections in animals, such as foot-and-mouth disease. Foot-andmouth viruses recovered from carrier animals are frequently $t s$, whereas the replication of isolates from animals with acute infections are generally not affected by temperature [64]. As Andre Lwoff proposed in 1959, the degree of virulence of viruses is often related to their level of thermal sensitivity (i.e. greater sensitivity to heat is correlated with reduced virulence) [65].

\section{Premise \#3: thermal sensitivity confines respiratory viruses to the nose and throat; coughing, sneezing and runny noses encourage transmission.}

Clearly, the human respiratory tract is normally colder than most other areas of the body. McFadden et al. showed that there is a temperature gradient that runs from the nostrils (which are close to the temperature of the air being breathed) to the lungs (which are at body temperature) [66]. For example, during quiet breathing of room air the lining of the upper trachea was at $32.0^{\circ} \mathrm{C}$, but the subsegmental bronchi were at $35.5^{\circ} \mathrm{C}$. The temperature of the respiratory tract fluctuated on each breath, and both breathing colder air and exercise rapidly reduced the temperature.

TDVT suggests that since most respiratory viruses are $t s$, they will not normally replicate in the lungs and internal organs. In 1979 Richman and Murphy pointed out that many naturally-occurring viruses were $t s$, and noted that $t s$ influenza, RSV, parainfluenza, and foot-and-mouth consistently replicated more rapidly in the nasal cavities of a variety of animals than in their lungs [30]. Many "live" vaccines use thermal sensitivity to attenuate the strains used, including avoiding lower respiratory tract infections. For example, FluMist, a live influenza virus vaccine, developed by Medlmmune Vaccines (formerly Aviron) in the early 2000s, uses a ts strain that replicates at $25^{\circ} \mathrm{C}$ and not body temperature, $37-39^{\circ} \mathrm{C}[67]$.

If respiratory viruses enter the bloodstream, TDVT predicts that they may settle and can replicate in cold parts of the body other than the respiratory tract, such as the skin or other extremities. Virulent human influenza strains occasionally cause rashes. For example, three children who were infected with pandemic H1N1 influenza in 2009 ("swine flu") presented with petechial rashes [68]. Chilblains are normally considered to be an inflammatory skin condition related to an abnormal vascular response to the cold. They typically present as tender red or bluish lesions located on the dorsal aspect of the fingers, toes, ears and nose [69]. TDVT suggests that at least some chilblains are caused by the replication of virus in the extremities and this has not been ruled out. Covid-19 is associated with chilblain-like symptoms referred to as "Covid toes" that mainly occur in older children and adolescents (Figure 11), although it has not yet been shown that they are caused by the presence of the virus in the feet. Figure 11 shows plaque-like blemishes of different sizes on the feet of a 16-year-old boy that may represent the sites where individual virions established replication. Covid-19 also causes a variety of other skin rashes and blisters [70].

TDVT also can shed light on the febrile response to infection. The response is well-preserved across the animal kingdom, and cues delivered by the thermal element of fever are known to stimulate both innate and adaptive immune responses [71]. It is, however, not clear why raised temperature is used as a protective signal in addition to chemical signals (cytokines and hormones). If, as suggested by TDVT, most respiratory viruses possess biochemistry that is inhibited by higher 
temperatures, fever may provide a direct benefit by slowing their replication, especially if they reach the warmer parts of the body such as the lower respiratory tract. It is interesting that reducing fever by the administration of antipyretics in a randomized prospective study in the ICU was associated with negative outcomes and increased mortality (although the trend was not statistically significant by rigid scientific criteria, $p=0.06$ ) [72].

\section{Premise \#4: ts respiratory viruses often remain dormant in the respiratory tracts of their hosts. If ambient temperature drops or hosts are chilled they may become active and cause sickness.}

Numerous studies have found that respiratory viruses are present in people, often without symptoms (i.e. dormant), during non-seasonal periods. Galanti et al. performed a large-scale community study across multiple age groups to assess the prevalence and pathogenicity of 18 common respiratory viruses in New York City from the fall of 2016 to the spring of 2018 [73]. The results were remarkable: on average, only $30 \%$ of detectable respiratory infections were symptomatic. Influenza and metapneumovirus were most pathogenic, with roughly $50 \%$ and $70 \%$ of cases being symptomatic respectively. A longitudinal analysis of the data found that roughly as many individuals were carrying respiratory viruses in summer as in winter [74]. Shaman and Galanti looked in detail at the symptoms caused by the four endemic human coronaviruses and found that the majority of infections were asymptomatic by most symptom definitions [75]. Other studies have detected a variety of viruses in asymptomatic individuals. For example, Granados et al. showed that asymptomatic rhinovirus activity preceded peak symptomatic activity in September and October and was associated with lower viral load [76]. Other studies identified asymptomatic individuals who had not seroconverted, but who were shedding influenza A [77-79] or influenza B [80]. Thai et al. commented that this "may indicate that viral RNA remained in the respiratory tract without being internalized and eliciting an immune response" [79].

Studies of respiratory viruses in Antarctica show dormancy and activation of respiratory viruses are possible under the right conditions of temperature; infections still occur even though they are rare due to lack of human contact after the first month of isolation. On one occasion, after 12 months of complete isolation a geologist at the Mawson station picked up a respiratory virus from a visiting field party [81]. He experienced no symptoms for 17 days, at which time he and three colleagues developed muscle aches and sore throats after being exposed to cold and damp conditions. Another study at Adelaide Island in 1969 found that after 17 weeks of complete isolation several men developed colds four days after the air temperature fell in one day from $0^{\circ} \mathrm{C}$ to $-24^{\circ} \mathrm{C}$ [82]. Muchmore et al. reported parainfluenza shedding by healthy young adults throughout the $81 / 2-$ month winter isolation period at Amundsen-Scott South Pole Station during 1978, with two episodes of respiratory illness caused by parainfluenza after 10 and 29 weeks [83]. These studies show that respiratory viruses can become dormant and suggest that they can be activated by low temperatures and host chilling, giving rise to respiratory illness.

Since dormant respiratory viruses are often present in the respiratory tracts of otherwise healthy individuals, and since TDVT suggests that such viruses will be activated by local temperature drops, the hypothesis predicts that cold-weather snaps will cause surges in respiratory disease (Figure 5). Moreover, chilling of individuals is likely to increase colds for similar reasons. In 1919, Mudd and Grant, two American doctors, reported that chilling of the body surface (for example by placing a wet towel on the back) caused a rapid reduction in the blood flow to the lining of the respiratory tract, together with a rapid fall in its temperature [84]. This physiological response may cause respiratory sickness after specific chilling events such as wearing wet clothing after rainfall, and may also exaggerate the effect of ambient temperature fluctuations.

An interesting observational study from 1997 by the Eurowinter Group examined the effect of exposure to cold on infection and illness caused by wild-type virus strains. The study applied the 
techniques of market research to find correlations between multiple cold-exposure factors and death from respiratory illness in seven regions of Europe, ranging from Northern Finland to Athens (Greece) [85]. The study found that factors that increased personal chilling such as standing still outside for more than two minutes $(p=0.04)$, wearing a skirt $(p=0.005)$, and shivering outside $(p=0.001)$ were significantly correlated with increased risk of death from respiratory illness (Figure 12). On the other hand, factors that reduced personal chilling such as wearing a hat outside $(p=0.004)$, wearing an anorak outside $(p=0.001)$ and outdoor exercise sufficient to cause sweating $(p=0.02)$ were significantly correlated with reduced risk of death from respiratory illness.

The finding that protection from viral infection is correlated with outdoor exercise with sweating is particularly interesting. This requires explanation by a combination of TDVT and the idea that personal chilling reduces our immunity (E3, above). TDVT says that breathing cold air will "wake up" dormant virions, while the lack of chilling and the good blood flow to the nose and throat (implicit in the stipulation of sweating) may ensure that batches of activated virions - presumably now visible to the immune system - can be destroyed by our defenses. Note that the Eurowinter Group found that frequency of going out was only slightly correlated with reduced mortality, suggesting that this apparent protective effect is not mainly (or only) driven by the regular elimination with exercise of activated virions in small batches [85].

Numerous studies from the 1950s and 1960s, however, including three influential studies by Andrewes, Dowling and Douglas [10-12], have been widely interpreted as showing that body chilling does not increase the chance that individuals will experience a cold from a viral infection. These studies were performed with volunteers who were inoculated nasally with suspensions of recycled cold viruses that were taken from previous volunteers. The authors called these "pedigree" strains. (The viral species involved was often unknown.) When individuals were inoculated and then subsequently chilled, the studies found that they were no more likely to get colds than individuals who were not chilled, leading the authors to conclude that chilling does not bring on colds. Since these experiments were designed to be carried out within a limited time-frame, often one week, and infections had to appear quickly if they were to be recorded, it has been suggested that fast-acting viral strains were selected by this procedure that had lost their natural thermal sensitivity at the point of binding or entry into cells [31]. It is therefore possible that chilling increases the risk of getting a cold caused by a "wild" virus, but not a cold caused by a virus such as was used in these studies.

The pattern of dormancy followed by low-temperature activation may explain the explosive arrival and abrupt termination of influenza epidemics recorded by Hope-Simpson and others (Figure 7). TDVT suggests that a virus such as influenza can enter a community either without symptoms or with only minor cold symptoms. If the temperature subsequently drops, symptomatic infections are triggered by the activation of dormant viruses. If the temperature then remains stable no further severe infections develop and the epidemic may end abruptly when the first batch of symptomatic illnesses are resolved. The TDVT hypothesis can therefore explain these observations of influenza epidemics, which are otherwise problematic.

After an initial peak in SARS-CoV-2 test positivity in the spring of 2020, rates of illness dramatically decreased during the summer months in most countries situated in temperate locations of the Northern Hemisphere [86]. However, cases were still found over the summer, and SARS-CoV-2 is estimated to cause completely asymptomatic infections in $17 \%$ of cases [87]. Case numbers remained low over the summer in many countries, perhaps because asymptomatic individuals were found to be $42 \%$ less likely to transmit the virus than symptomatic individuals. In the autumn, Covid19 surged in those countries. (The new cases may have comprised both dormant infections that had been activated by temperature, and new infections transmitted from these newly-activated cases.) Meanwhile, countries south of the Equator such as Brazil, Chile and Peru experienced major Covid19 epidemics during their cold season (April - October 2020). These observations suggest that 
despite being a recent "spill-over" to the human' species, SARS-CoV-2 has retained or gained significant thermal sensitivity.

\section{Conclusion}

\section{Seasonality of respiratory viruses is a result of thermal sensitivity. Natural selection based on thermal sensitivity allows respiratory viruses to adapt to local climate conditions.}

As stated previously, any description of the epidemiology of respiratory viruses needs to explain why: (1) in temperate locations colds and flu are seasonal, and there is, frequently, a sudden epidemic of colds and flu in the autumn; (2) roughly the same set of viruses cause respiratory illness all over the world (Table 2), including tropical and temperate locations, yet ambient temperature in those locations varies greatly; (3) there is a rapid response of viruses to local weather; and (4) viral outbreaks often begin and end suddenly. Previously suggested explanations assign cause to crowding, enhanced virus survival in the winter, and/or weakened immune systems. However, each of these explanations has flaws when compared to the data on respiratory illnesses.

The four premises of Temperature-Dependent Viral Tropism (TDVT), presented here, explain these characteristics of respiratory illness by suggesting that (1) mildly pathogenic endemic viruses are more likely to be transmitted; (2) most respiratory viruses use thermal sensitivity to moderate their pathogenicity; (3) thermal sensitivity helps respiratory viruses stay in the nasal cavity and throat, where they can be transmitted; (4) viruses are often present but dormant in the nose and throat and can cause sickness if ambient temperature drops or hosts are chilled.

The autumn surge of respiratory illness in temperature locations can be explained by TDVT if we assume that viruses with a particular level of thermal sensitivity are selected according to the weather/climate, and that this process takes place within a few months. During the hotter weather of summer, the few wild-type viral strains with low thermal sensitivity are likely to be selected because only less-ts strains are active at higher temperatures and able to replicate and be transmitted. Other viral strains that are more ts may be dormant at this time. (Note that the strains that we refer to as "less-ts" nevertheless retain significant thermal sensitivity. TDVT suggests that if they were to lose all thermal sensitivity they would become highly pathogenic, comparable to the viruses that cause Ebola and other hemorrhagic fevers.) When ambient temperature falls in autumn, the temperature in the nose and throat also falls and the respiratory viruses that are already present quickly become more active, causing an increase in transmission and illness. In winter, the situation changes: the most virulent (less ts) strains now immobilize their hosts, so the more $t s$ (less virulent) strains are most likely to be transmitted. When ambient temperature rises in the spring, these more ts viruses become less active and the number of colds is reduced. The net result is more colds and flu in winter, fewer in summer, with a surge in autumn. Figure 13 shows these trends schematically.

According to TDVT, respiratory viruses adapt to their local ambient temperature, so we can expect them to spread throughout the world over time and establish reasonably stable equilibria in all locations (albeit disturbed by seasonal temperature fluctuations in temperate locations). Figure 14 shows that influenza strains move freely around the world. Figure 14 also shows that influenza strains are more likely to move from hotter to colder locations than in the opposite direction. This is predicted by TDVT because tropical strains need to be less ts to replicate in nose and throat at higher temperatures, and they are therefore intrinsically more virulent and expected to cause more serious illness if they are transported to temperate locations. Note that the same virus might colonize locations nearer the (cooler) nose in the Tropics, and nearer the (warmer) lungs in cold locations.

Studies that attempt to explain the influence of weather, seasonality, and environmental influences on Covid-19 have yielded contradictory and confusing results [22]. For example, Pan et al. looked at 
Covid-19 cases in 202 locations in 8 countries, with matching meteorological data, and found that temperature did not exhibit significant associations with Covid-19's R0 [88]. However, Guo et al. looked at meteorological factors and Covid-19 incidence in 190 countries and concluded that a higher temperature was associated with a lower incidence of Covid-19 [89]. Ward et al. determined that humidity has a significant effect on SARS-Cov2 spread in Australia [90], but Jamshidi et al. did not find that weather was a significant factor [91]. Note that many meteorological studies examined absolutes of humidity and temperature, not fluctuations. At the start of the pandemic, seasonality may have also been less important because SARS-CoV-2 could spread in any climate and season due to lack of immunity. However, the virus may now have begun to adapt its thermal sensitivity to local climates and seasons.

The autumn surge of colds (Figure 2) suggests that natural selection can adjust the thermal sensitivity of respiratory viruses within a few months. Since too high pathogenicity may reduce viral transmission (as patients become bed-ridden), natural selection may adjust thermal sensitivity to a level that is appropriate to the virus's location, season and climate. These explanations fit the experimental data and observations of viral outbreaks with more rigor than previously offered arguments in favor of crowding, viral survival or immune defenses.

\section{Practical recommendations suggested by TDVT for avoiding and treating respiratory illnesses}

\section{The TDVT hypothesis makes the following suggestions for avoiding respiratory illness (see Figure 12):}

1. Dress warmly to avoid chilling [85]. The body rapidly reduces the blood flow to the respiratory tract during chilling, reducing the temperature of the lining of the respiratory tract [84]. TDVT says chilling will cause dormant respiratory virions to become active and begin to replicate.

2. Avoid standing still outdoors in cold temperatures [85].

3. Take regular outdoor exercise sufficient to cause sweating [85]. The reason that this is correlated with a reduced chance of death from respiratory illness is unknown, but it seems likely that breathing cold air activates dormant virions - making them visible to the immune system - while dressing warmly improves immune defenses in the respiratory tract [31]. Regular outdoor exercise with warm clothing may therefore allow respiratory virions to be eliminated in small batches. Note that the combination of cold air and warm clothing seems to be protective.

\section{Suggestions from TDVT for treating existing respiratory illness:}

1. Keep the temperature of the patient constant and warm.

2. Do not take exercise when symptoms begin. The respiratory symptoms indicate that the immune system is already actively removing viruses from the respiratory tract. Rapid breathing cools the respiratory tract [66] and it would be unhelpful to increase the load by activating more virions.

3. Keep the air in the sick-room warm to increase the blood flow to the respiratory tract [84].

4. Drinks should be at room temperature or warm, not hot.

a. Iced or chilled drinks and ice-cream etc. may cool the throat and encourage viral replication.

b. The higher temperatures of hot drinks may activate some steps in the lifecycle of respiratory viruses. For example, several studies showed that the production of influenza viral proteins increased at temperatures above the normal temperature of the respiratory tract $[51,55,56]$. 


\section{Future Work for the Validation of the TDVT Hypothesis}

The TDVT hypothesis is testable at many levels, and suggestions for experiments have already been made [31]. Important suggestions to test the hypothesis include:

1. Investigate the best temperatures for propagating newly-isolated respiratory viruses in tissue cultures.

2. Infect animals with labelled respiratory viruses and determine the positions of replicating viruses in the respiratory tracts of animals that have experienced different temperature regimes (such as temperature step-up and step-down time-course experiments, see Figure 9B).

3. Follow viral entry, transcription, splicing, translation, genomic replication, assembly and release of daughter virions from cells in temperature step-up and step-down time-course experiments (Figure 9B).

4. Investigate of the effect of mutations on temperature-sensitivity, including effects on RNA secondary structure, possibly using DNA-based "recombinant" systems (because DNA sequences are much more stable than the RNA sequences of replicating viruses).

5. Randomized controlled studies to test the suggestions for avoiding and treating respiratory illnesses (e.g. randomized controlled studies where healthy individuals are chilled to see if this results in increased respiratory illness arising from the "wild" respiratory viruses that they happen to be carrying at the time of the experiment). 
Mainz, Germany, 2000 - 2008 (oceanic climate) du Prel, Clinical Infectious Diseases 49.6 (2009): 861-868.

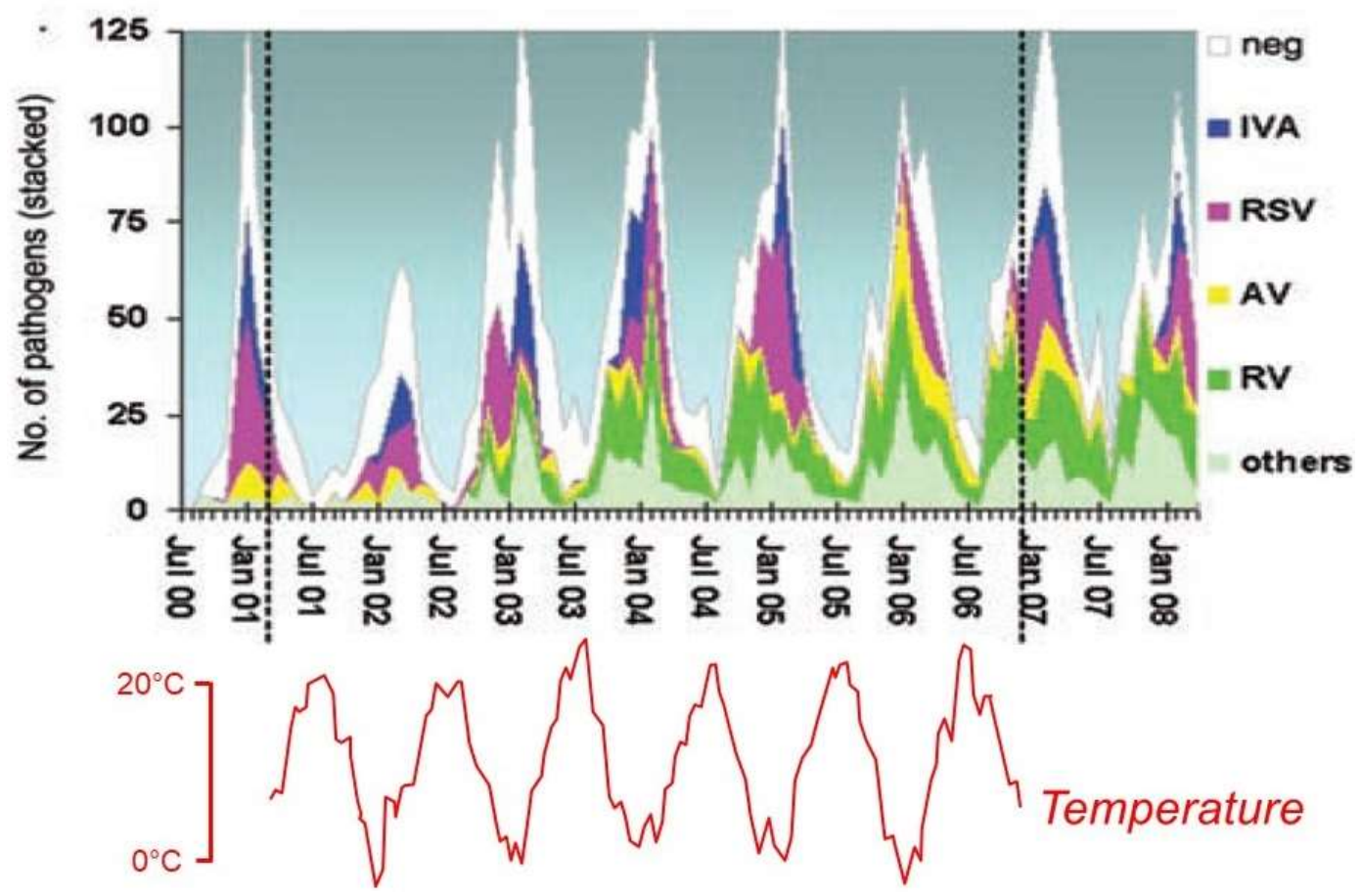

Figure 1: An example of winter seasonality: the viruses that caused respiratory tract infections in hospitalized children in Mainz, Germany, which has an oceanic climate, $2000-2008$. Note that the timing of illness caused by particular viral species is variable. For example, RSV hospitalizations mainly occurred before 1 January in the winter of 2002/03, but after 1 January from 2005 onwards. Nevertheless, the maximum for all hospitalizations was normally around February, and the minimum around August. Adapted from du Prel JB et al. Clin Infect Dis 2009; 49(6):861-8 [16]. 

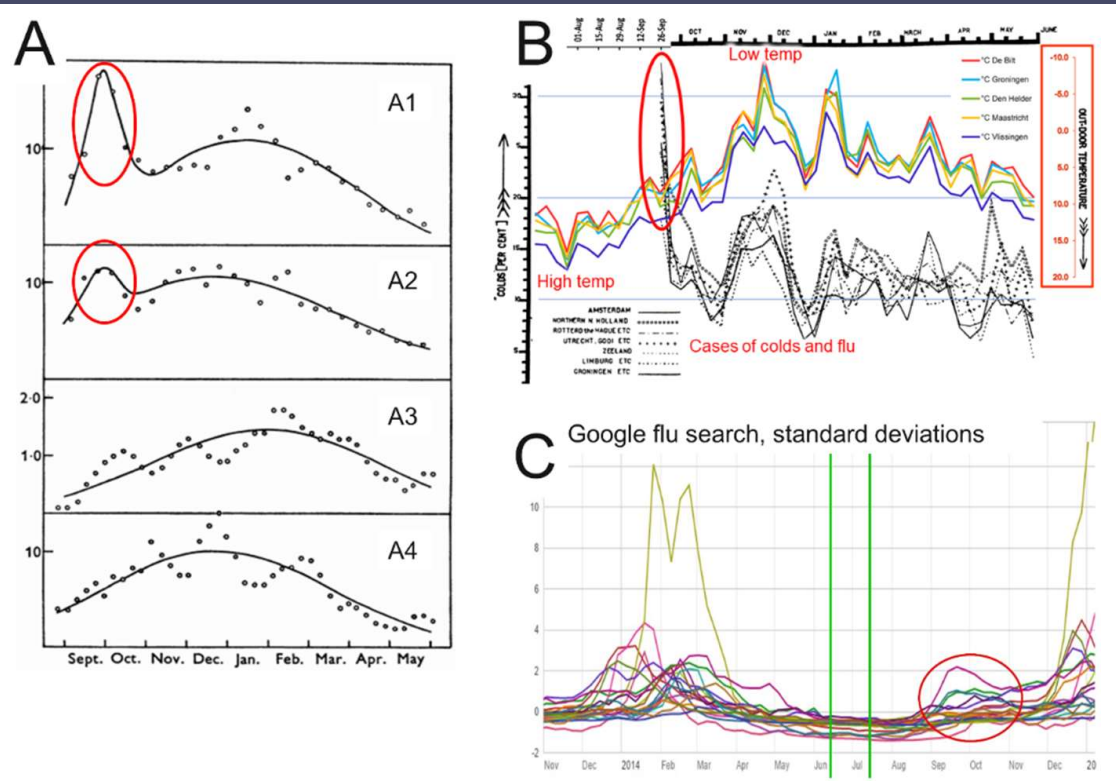

Figure 2: four datasets that show an "autumn surge" in the number of colds (red ovals). (A) Graphs show the average yearly incidence of colds for each period of 10 days +/- 1 day [7]. A1: London, 1951-1955; A2: Newcastle, 1951-1957; A3: Cirencester, 1954-1956; A4: Chalke valley, 1948-1949. Note that for London and Newcastle the number of colds at the end of September was greater than or equal to the number in midwinter. For details see the original paper. However, the trend is not universal, and in Cirencester and Chalke valley smaller autumn surges were seen. (B) At the beginning of van Loghem's study in September 1925 one third of respondents in Amsterdam had colds, with high numbers in some other regions (red oval) [20]. For more information see the legend of Figure 5. (C) In September 2014 Google "flu search" activity increased in most countries in the Northern Hemisphere (red oval). For more information see the legend of Figure 3. Section $(A)$ is adapted from Epidemiology \& Infection, 1965 Sep;63(3):427-39 [7], while section (B) is adapted from Epidemiology \& Infection, 1928 Aug;28(1):33-54 [20]. (C) Was retrieved in August 2015. 


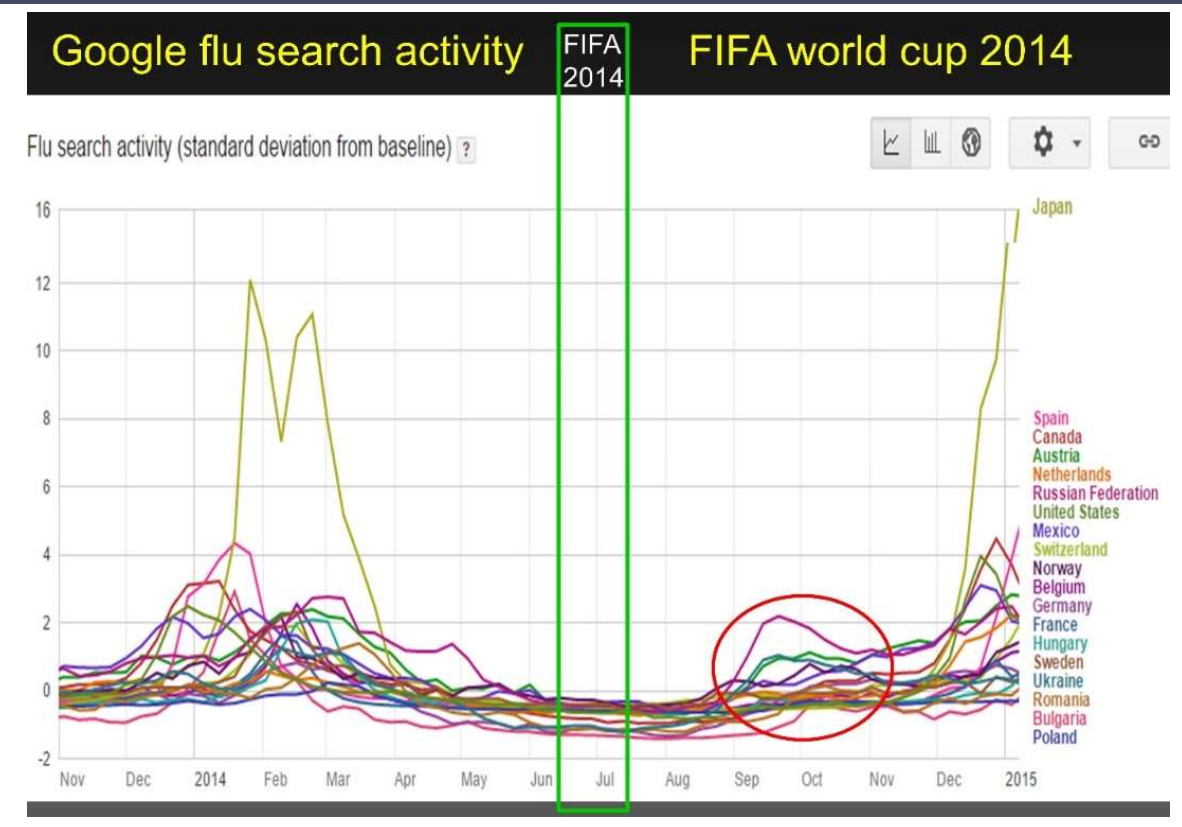

Figure 3: Google "flu search" activity during FIFA 2014. Google flu search measured the number of people who search for terms related to colds and flu using the Google search engine. During major sporting competitions people often crowd together in bars and at home to watch the events. The figure shows that during the 2014 FIFA World Cup, in the 18 countries in the Northern Hemisphere where flu search activity was reported, there was no increase in the number of Google searches for related terms. This suggests that the epidemics that are apparent in winter in every country are not mainly driven by crowding (E1). Notice the epidemics of colds in September 2014 (red oval).

Autumn epidemics quite often appear when the temperature dips at the end of summer (Figure 2). 


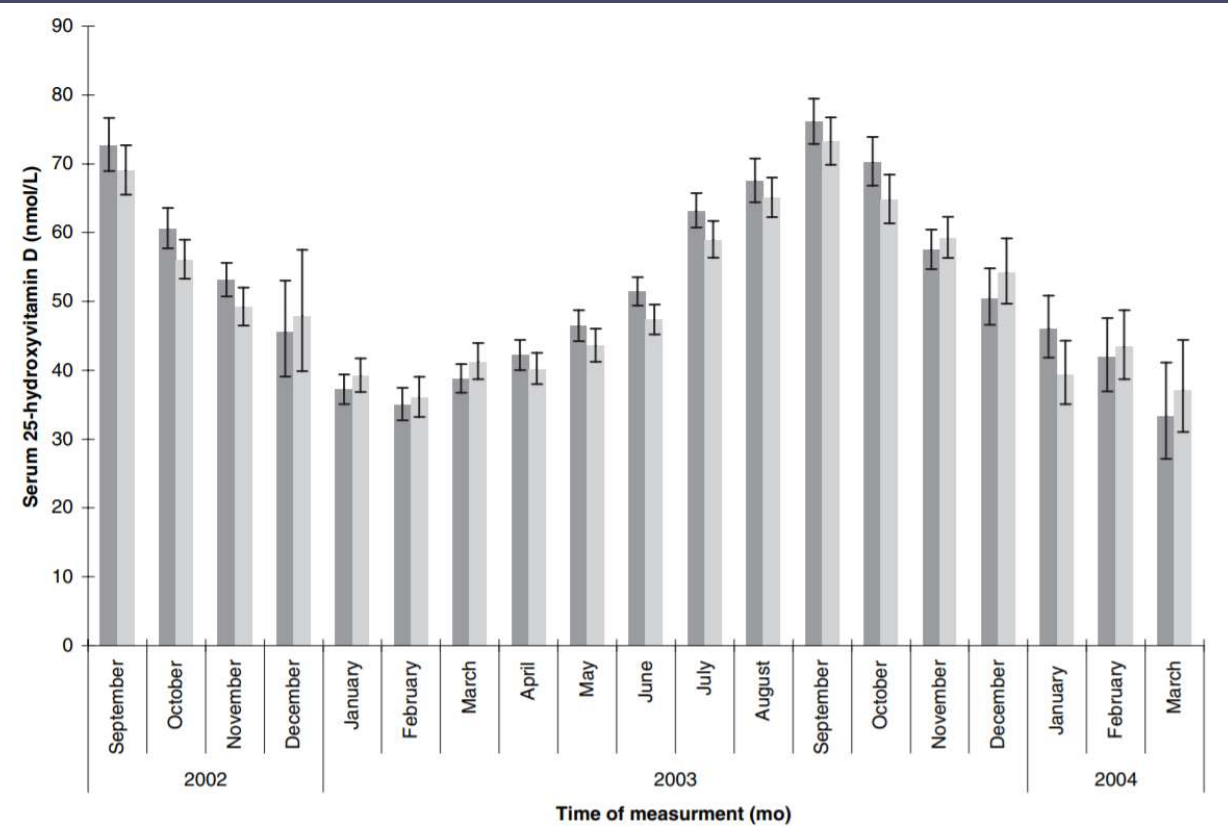

Figure 4: monthly serum levels of vitamin D in men (dark grey) and women (light grey). Note that (1) vitamin $D$ levels change slowly over several months without major fluctuations that would result from the influence of short-term changes in the weather (although in a few cases the increases and decreases are not monotonic); (2) the highest vitamin D levels were in September, which coincides with the yearly surge in the number of colds that frequently appears during that month (see figure 2). This suggests that vitamin $D$ is not the main driver of viral winter seasonality. This figure was originally published in Am J Clin Nutr 2007, 85: 860-868 [13]. 


\section{Netherlands, 1925 - 1926}

Van Loghem, J. J. Epidemiology \& Infectior 28.1 (1928): 33-54.

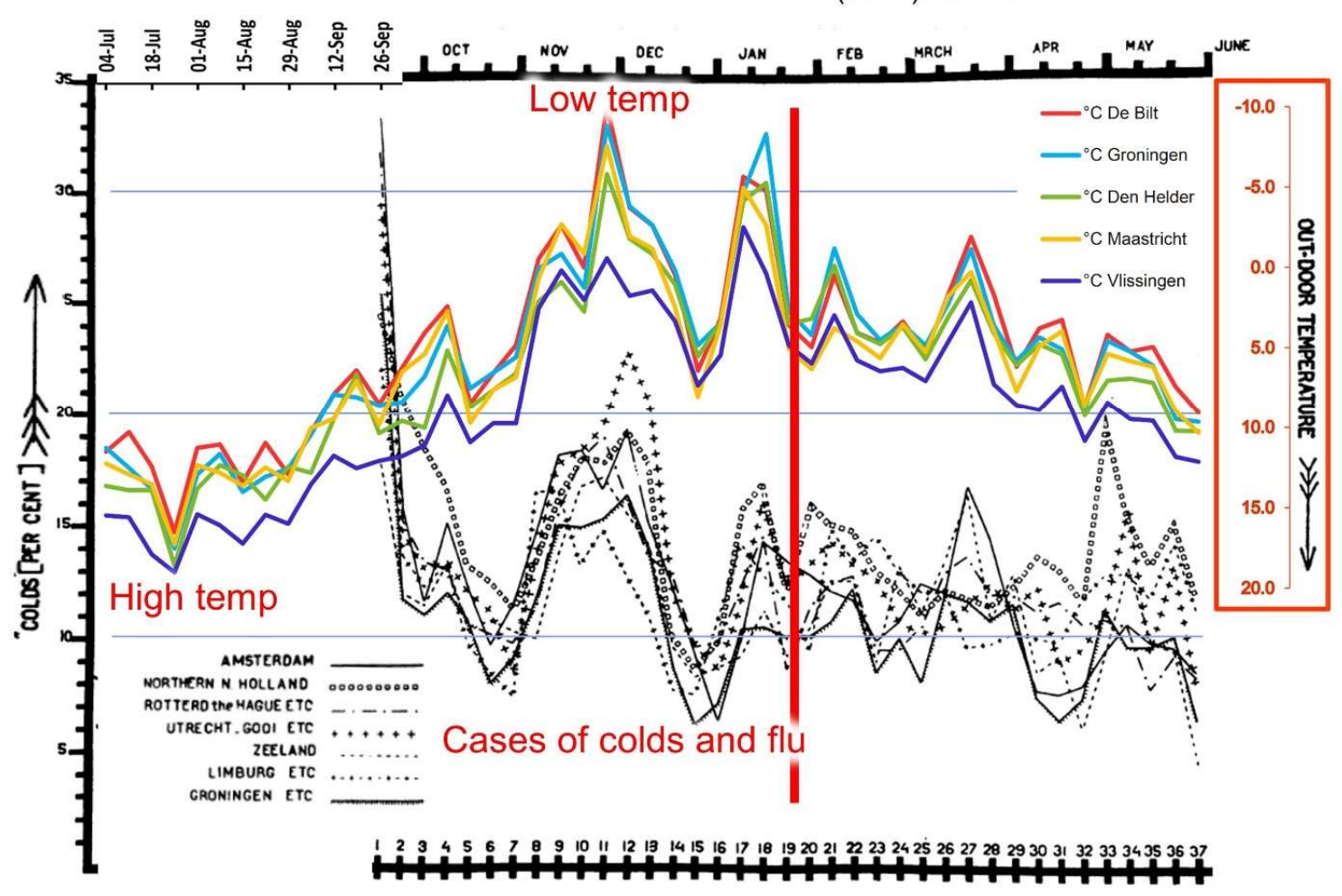

Figure 5: Graph II from van Loghem's report on the epidemiology of respiratory illnesses in the Netherlands in the winter of $1925 / 26$. I have superimposed the ambient temperatures recorded at five Dutch weather stations (colored lines) with the temperature scale inverted (lowest temperatures at the top). Note that (1) by far the highest number of illnesses in the whole study was at the very beginning, in September 1925; (2) there is an extraordinary correlation between ambient temperature, and colds and flu throughout the Netherlands; (3) colds and flu arrived in all areas of the Netherlands almost simultaneously, with illnesses synchronized to within $1-2$ weeks at some points; (4) the correlation is strongest in the first part of the cold season. After the red line the relationship between temperature and colds became less clear. Adapted from Epidemiology and Infection 28(01), 33-54. 


\section{Prevalence of influenza}

\section{SE NW}
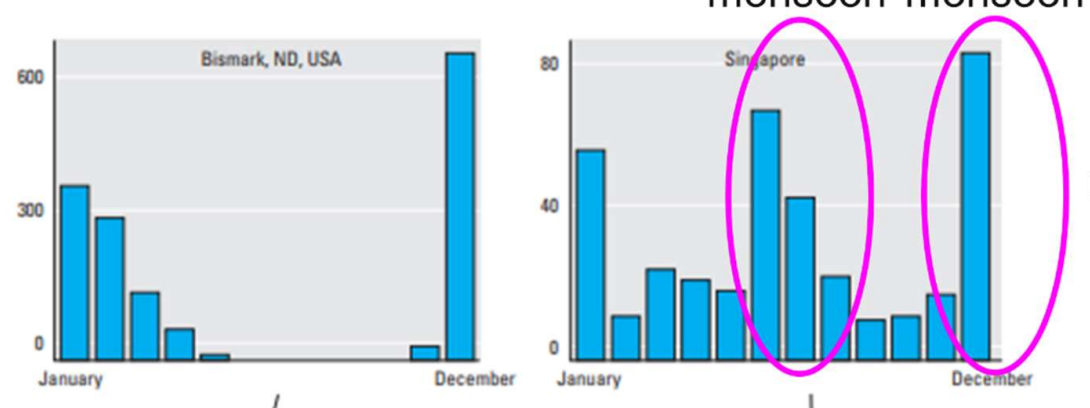

Wind and rain cause personal chilling
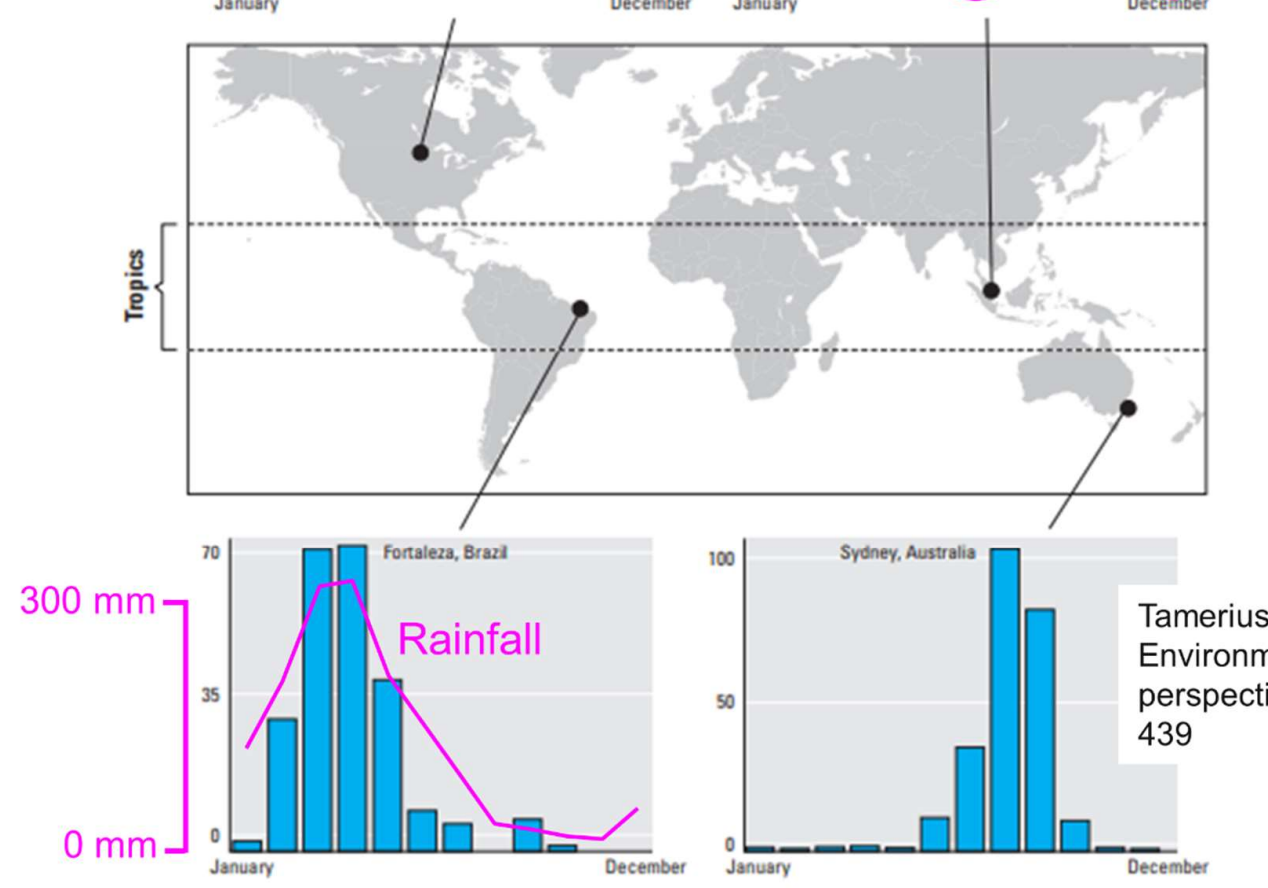

Figure 6: seasonal patterns of influenza in four sites across several latitudes worldwide. In temperate regions epidemics normally occur during the winter months. Seasonal influenza activity in the tropical locations is greatest during the rainy season. The bar charts indicate the average number of detected influenza isolates ( $y$-axis) over several years for Singapore, Fortaleza (Brazil), Bismarck (North Dakota, USA) and Sydney (Australia). Rainfall in Fortaleza and the two monsoons in Singapore are shown in purple. Adapted from Environmental health perspectives, $2011 \mathrm{Apr}$; 119(4):439-45 [2]. 
The 8 largest influenza outbreaks in Cirencester, UK 1946-74.
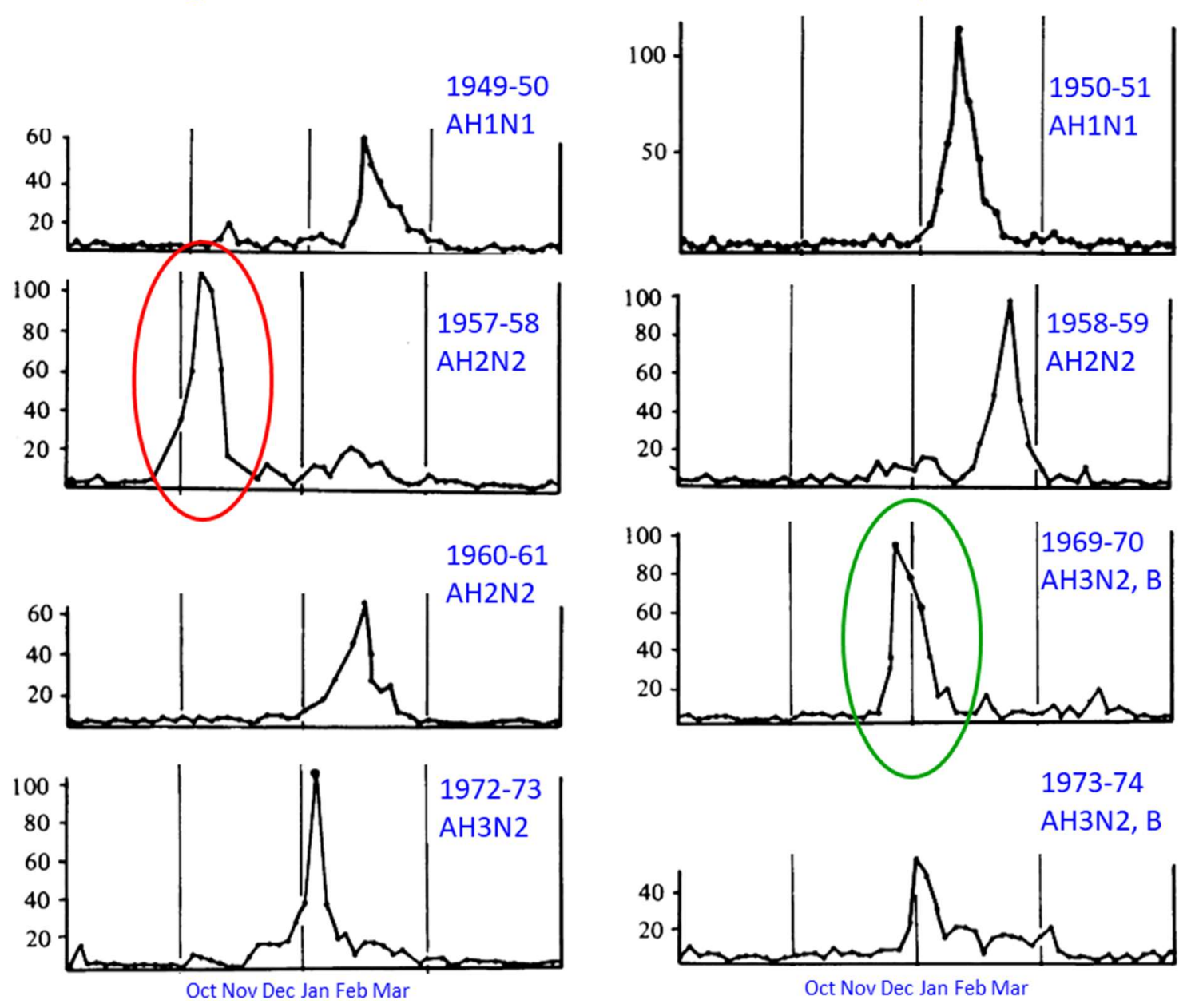

Figure 7: the eight largest influenza outbreaks in Cirencester, UK, 1946-1974. The graphs show the number of patients treated for acute febrile respiratory illness. It can be seen that influenza epidemics sometimes arrive in just $2-3$ weeks and terminate in a similar time period. The red oval shows the arrival of Asian flu, green, the first major epidemic of Hong Kong flu (which arrived the previous year). Adapted from Epidemiology \& Infection, 1981 Feb;86(1):35-47 [19]. 

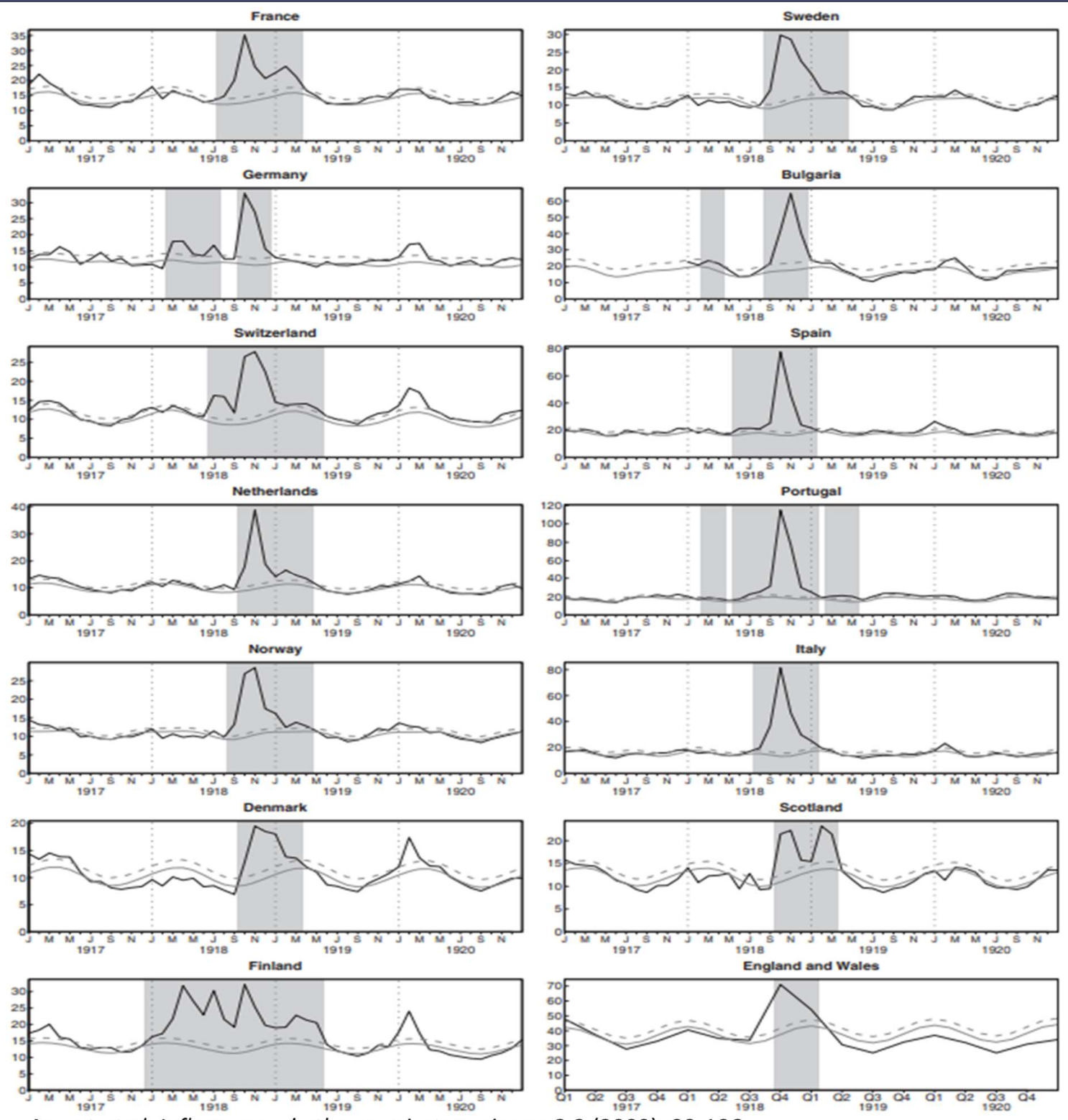

Ansart et al. Influenza and other respiratory viruses 3.3 (2009): 99-106.

Figure 8: mortality rate (black line) in 14 European countries during the Spanish Influenza epidemic, 1917-1920. The continuous grey line shows predicted mortality, the dashed grey line the pandemic threshold (for more information see the original paper) [26]. Note that most countries only experienced one main peak, occurring in the same two-month period, and that epidemics the following winter were much smaller and only apparent in four countries. Mortality in Finland is difficult to interpret during and after the Finnish Civil War (January to May 1918). A common explanation for the rapid termination of this epidemic is that almost the whole population was exposed to the virus, and that individuals either died or acquired immunity. However, recent studies have suggested that the extreme pathogenicity of Spanish flu arose from the unusual selective conditions that existed in the armed forces during World War I [26], and the disease's pathogenicity may have decreased when increased immunity in the population encouraged the natural selection of milder strains, as suggested by TDVT (and the well-known "trade-off" hypothesis, see main text). This figure was originally published in Influenza and Other Respiratory Viruses, 2009 May;3(3):99106 [26]. 


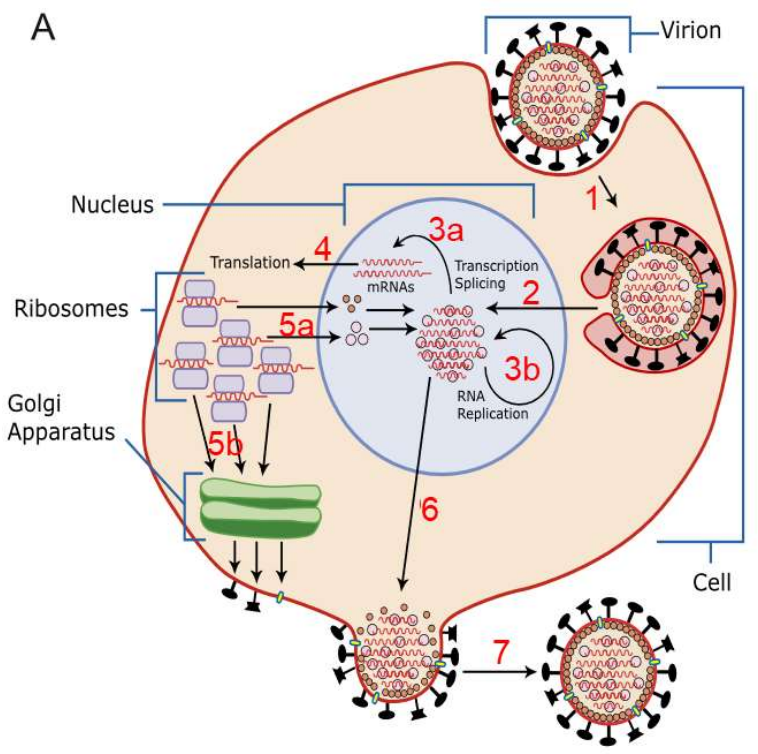

B

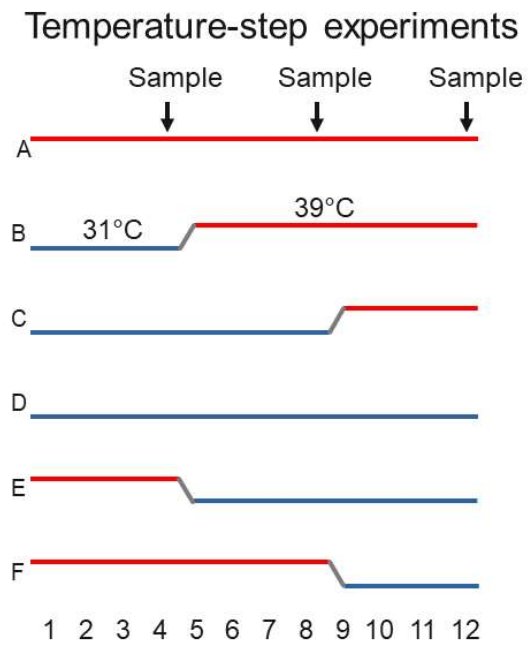

Figure 9: (A) steps in the life-cycle of respiratory viruses that might be thermally sensitive ( $t s$ ).

Experiments will be needed to determine which steps in the life-cycles of any particular respiratory virus are $t s$. The diagram shows influenza virus in a cell as an example. All steps, numbered 1-7, might be $t s$. Note that the secondary structure of RNA is inherently ts, so steps involving RNA are good candidates to be involved in ts responses. Steps 1, 3 and 4 have previously been found to be $t s$ in influenza in the laboratory (see main text for details). (B) Temperature step-up and step-down experiments using cell-cultures and/or animals can investigate the thermal sensitivity of each step of a virus's life-cycle. Data can be collected periodically after incubation at high or low temperatures (arrows). 


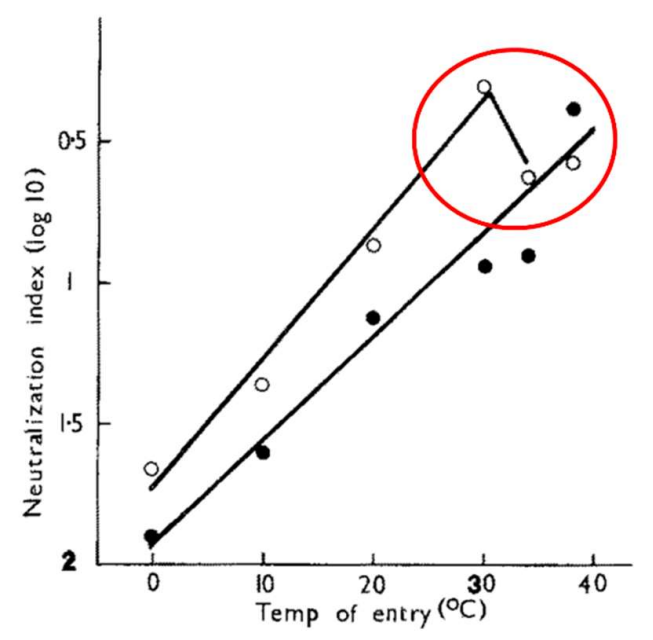

Figure 10: The effect of temperature on influenza virus entry into cells. Influenza virus was preadsorbed to MDBK cells at $0^{\circ} \mathrm{C}$ and then pulsed at varying temperatures of up to $38^{\circ} \mathrm{C}$ for 120 minutes [46]. Entry into cells was assessed by any escape from subsequent neutralization using a monoclonal antibody to haemagglutinin. Circles show the triple reassortant influenza virus $\mathrm{A} / \mathrm{Jap} / \mathrm{Bel}$, black dots the double reassortant A/NIB-8. Note that, (red oval), at $34^{\circ} \mathrm{C}$ and $38^{\circ} \mathrm{C}$ less $\mathrm{A} / \mathrm{Jap} / \mathrm{Bel}$ escaped neutralization by MAb by entering cells than at $30^{\circ} \mathrm{C}$. This was repeated on two separate occasions using a chicken anti- $\mathrm{H} 2$ serum when 100 per cent of virus escaped neutralization at $30^{\circ} \mathrm{C}$ as compared to 50 per cent at $38^{\circ} \mathrm{C}$ (results not shown). A/NIB-8 entry was not ts and cell entry increased monotonically with temperature. This is one of many reports of unexplained thermal sensitivity of respiratory viruses. Other examples are given in the main text. This figure was originally published in Arch Virol 1986;88(3-4):159-66 [46]. 


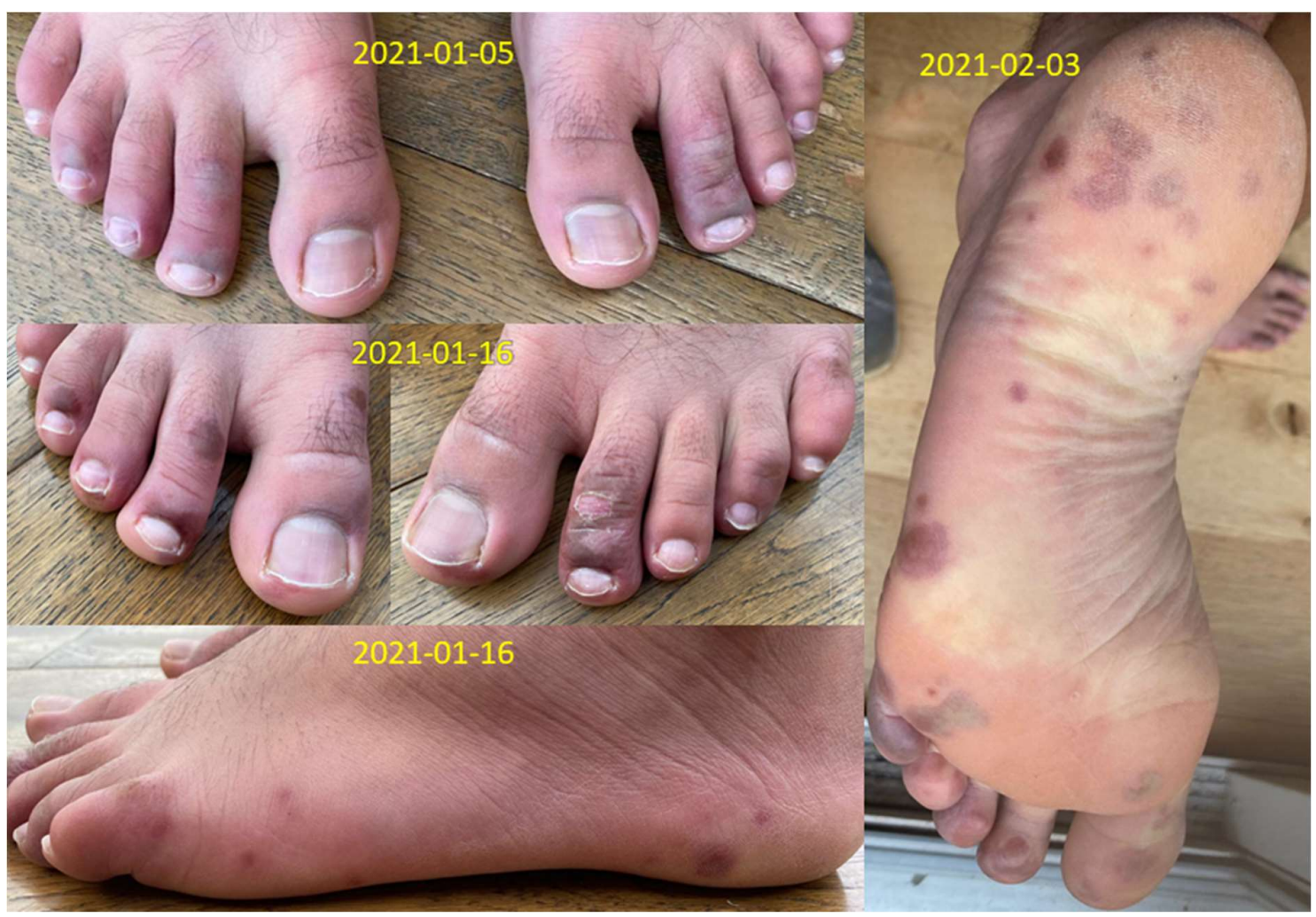

Figure 11: Covid toes, showing discoloration of the feet of a 16-year-old boy. He felt completely well, but a blood test showed the presence of a viral infection. He usually did his schoolwork wearing socks without shoes. So-called Covid toes are blemishes that sometimes appear on the hands and feet, usually pink or purple, after exposure to SARS-CoV-2. They are most common in older children and adolescents. Note the peeling of dead skin on the second toe, and the plaque-like appearance of blemishes of varying sizes that are scattered around the feet. The TDVT hypothesis suggests that CoV-2 virions that may reach the bloodstream are more likely to bind to and invade cells in colder parts of the body, causing these visible symptoms. According to this interpretation each blemish represents a site where a single virion established replication. 
Donaldson, G. (1997). The Eurowinter Group. Lancet, 349, 1341-1346

\begin{tabular}{|l|r|r|}
\hline Cold exposure factor & \multicolumn{1}{|c|}{$\mathbf{R}$} & p-value \\
\hline Mean duration of going out & 0 & 0.922 \\
\hline Living room temperature & -1.8 & 0.001 \\
\hline Frequency of going out & -1.9 & 0.116 \\
\hline Whether going out & -2 & 0.623 \\
\hline Clothing area (fraction of & & \\
body surface) & 2.2 & 0.183 \\
\hline Bedroom heating & -2.8 & 0.053 \\
\hline Long underpants & -3.8 & 0.022 \\
\hline Gloves & -3.9 & 0.065 \\
\hline Long-sleeved vest & -4.5 & 0.072 \\
\hline Hat & -4.7 & 0.004 \\
\hline Long trousers & -6.6 & 0.005 \\
\hline Anorak & -6.7 & 0.001 \\
\hline Overcoat & 7.3 & 0.002 \\
\hline Skirt & 8.3 & 0.005 \\
\hline Sweater & 9.5 & 0.001 \\
\hline Stationery >2 mins & 13.2 & 0.04 \\
\hline Sweating outside & -17.5 & 0.02 \\
\hline Shivering outside & 23.8 & 0.001 \\
\hline
\end{tabular}

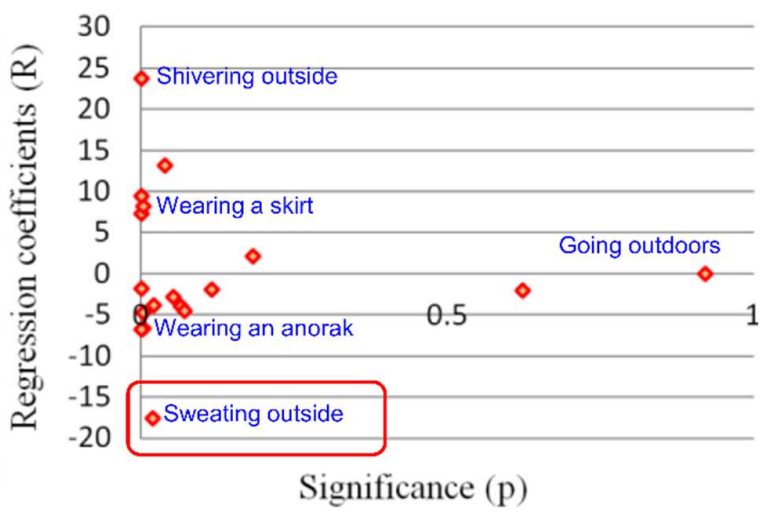

Above: the regression coefficients of mortality due to respiratory disease on 18 personal coldexposure factors, plotted against their significance.

The group used market research techniques to study respiratory illness in 8 European regions, from Northern Finland to Athens.

Figure 12: the regression coefficients $(R)$, and their significance $(p)$, for cause-specific indices of respiratory disease-related mortality on personal cold-exposure factors standardized at $7^{\circ} \mathrm{C}$ mean daily temperature in eight European regions, ranging from northern Finland to Athens [85]. The Eurowinter Group used market research techniques to analyze the climate and the measures taken to protect individuals from low temperatures. Some points are labelled on the plot on the right to illustrate trends. The activities that are most strongly correlated with dying from a respiratory illness are at the top left of the plot, while those that appear to be protective are at the bottom left. Activities that are not correlated with either an increased or decreased chance of dying are on the right or at the middle level. 


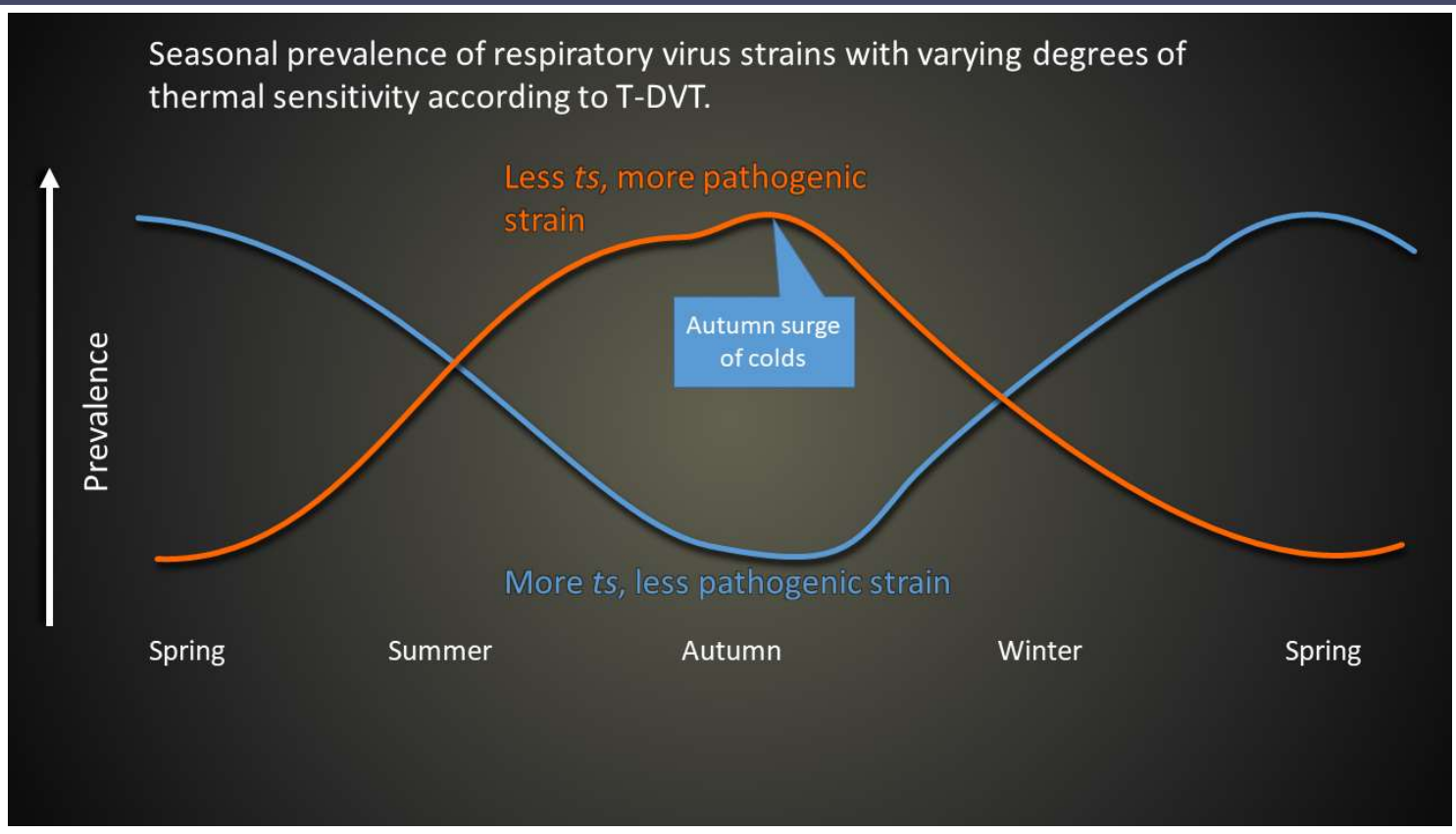

Figure 13. Schematic illustration of the seasonal prevalence of respiratory virus strains with varying degrees of thermal sensitivity, as predicted by the TDVT hypothesis. Two representative strains are shown, one less ts (therefore more pathogenic) and one more ts (therefore less pathogenic). In reality there would be many strains with varying degrees of thermal sensitivity, and mutations would frequently generate new strains from existing ones with differing thermal properties. During summer the more $t s$ strains replicate very little and become rarer, while more ts strains become more common. In autumn, a surge of colds is often experienced as the less ts strains that have accumulated over the summer are activated by the exposure of hosts to lower ambient temperatures. During winter, both strains can replicate, but the more $t s$ strains increase for a different reason: they are less likely to immobilize their hosts. 


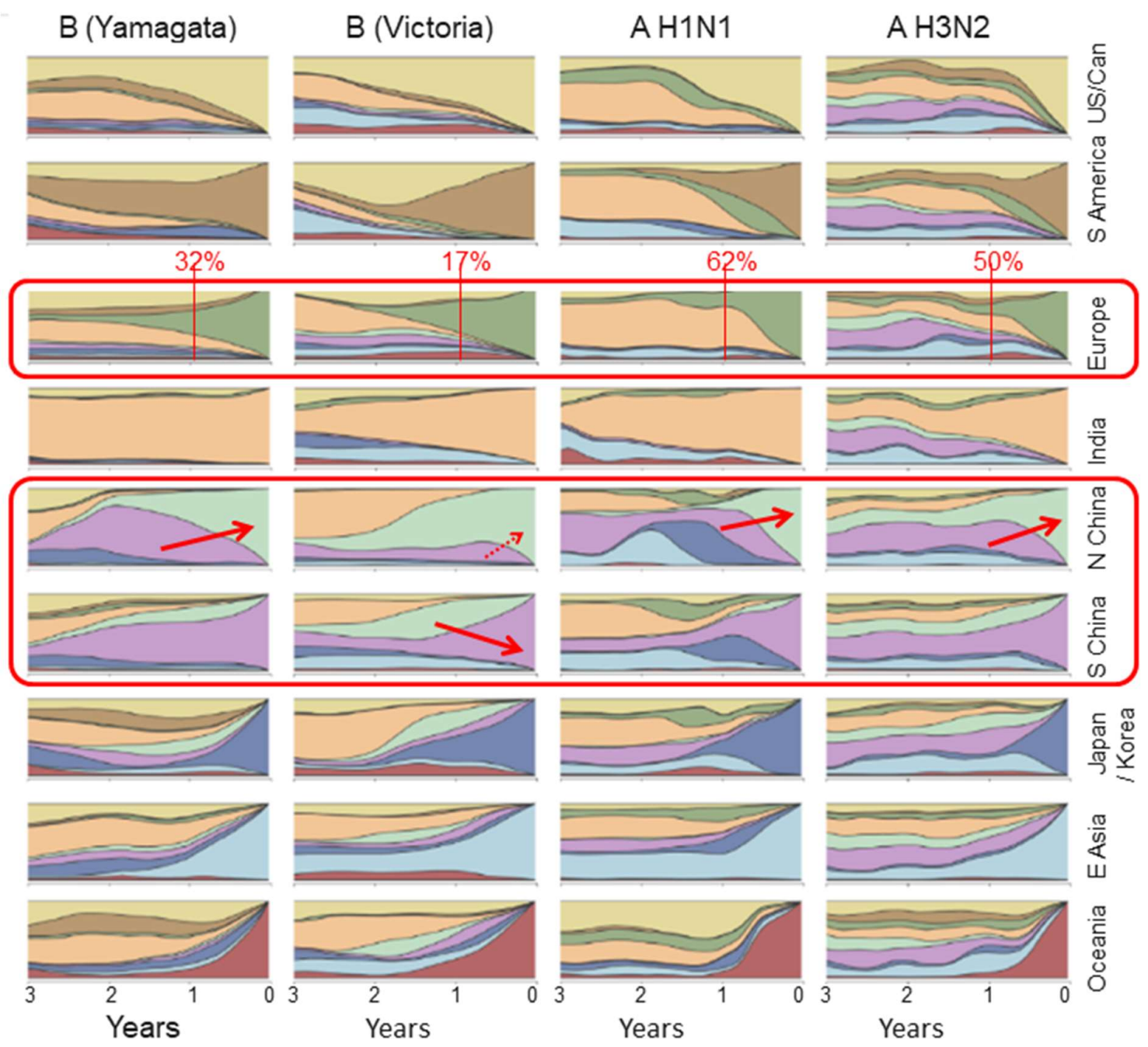

Figure 14: global movement of influenza strains. The authors have divided the world into 9 regions, and, by analyzing the sequences of viruses that were sampled worldwide over three years, they charted the movement of influenza strains. The region where each virus was sampled is color coded, and the colors show where the ancestors of current viruses (in each region) came from as you go back in time. The numbers at the bottom show years before arrival of the strain in the region under consideration. The right-hand side of each box is only colored with the region's own color because strains have had no time to move. As you go to the left the colors show where the ancestral viruses were at the time indicated. For example, "Yamagata-like" influenza B viruses in India (fourth row, first column) moved very little during the study, with most viruses at the end being descended from strains that were also in India at earlier times. At the other extreme (bottom right box), almost all H3N2 influenza in Australia had come into the country during the previous year. The figure shows some interesting trends. For example, we can see that influenza tends to move from hotter countries to colder ones. For example, a lot of European strains came from India and other hot countries: $32 \%$ of Yamagata-like B strains, $17 \%$ of Victoria-like B strains, $62 \%$ of H3N2 A strains, and $50 \%$ of H1N1 A strains that were present in Europe at the end of the study came from strains that were in tropical or subtropical regions one year earlier. You can also see that in three out of four cases, more strains move from South China to North China than in the opposite direction (indicated by red arrows). The flow is not in one direction only, however. European and US strains can also make their way to South China and India, although movement in this direction is less frequent. Adapted from Nature, 2015 Jul;523(7559):217-20 [92]. 


\begin{tabular}{|c|c|c|c|c|}
\hline Family & Genome & $\begin{array}{l}\text { Site of genomic } \\
\text { replication }\end{array}$ & Envelope & Form \\
\hline Adenovirus & Double-stranded DNA & Nucleus & Lacking envelope & Icosahedral \\
\hline $\begin{array}{l}\text { Coronavirus, SARS virus, } \\
\text { COVID-19virus }\end{array}$ & $\begin{array}{l}\text { Positive-sense single- } \\
\text { stranded RNA }\end{array}$ & Cytoplasm & Enveloped & $\begin{array}{l}\text { Spherical with } \\
\text { projections }\end{array}$ \\
\hline $\begin{array}{l}\text { Varicella Zoster Virus } \\
\text { (chickenpox) }\end{array}$ & Double-stranded DNA & Nucleus & Enveloped & Icosahedral \\
\hline Influenza virus & $\begin{array}{l}\text { Negative-sense single- } \\
\text { stranded RNA }\end{array}$ & Nucleus & Enveloped & $\begin{array}{l}\text { Spherical or } \\
\text { filamentous }\end{array}$ \\
\hline $\begin{array}{l}\text { Measles, mumps, } \\
\text { Parainfluenza, respiratory } \\
\text { syncytial viruses, human } \\
\text { metapneumovirus }\end{array}$ & $\begin{array}{l}\text { Negative-sense single- } \\
\text { stranded RNA }\end{array}$ & Cytoplasm & Enveloped & $\begin{array}{l}\text { Spherical or } \\
\text { variable }\end{array}$ \\
\hline Rhinovirus & $\begin{array}{l}\text { Positive-sense single- } \\
\text { stranded RNA }\end{array}$ & Cytoplasm & Lacking envelope & Icosahedral \\
\hline Rubella virus & $\begin{array}{l}\text { Positive-sense single- } \\
\text { stranded RNA }\end{array}$ & Cytoplasm & Enveloped & Icosahedral \\
\hline
\end{tabular}

Table 1: Some characteristics of common respiratory viruses that have winter seasonality.

\begin{tabular}{|l|l|l|l|}
\hline \multicolumn{1}{|c|}{ City } & \multicolumn{1}{|c|}{ Reference } & Climate & \multicolumn{1}{|c|}{$\begin{array}{c}\text { Most common respiratory viruses } \\
\text { causing hospitalization of children }\end{array}$} \\
\hline Singapore & $\begin{array}{l}\text { Chew FT et al. Epidemiol Infect } \\
1998 ; 121(01): 121-8 .\end{array}$ & Tropical & RSV, parainfluenza, influenza A, adenovirus \\
$\begin{array}{l}\text { Buenos Aires, } \\
\text { Argentina }\end{array}$ & $\begin{array}{l}\text { Viegas M et al. J Infection 2004; } \\
49(3): 222-8 .\end{array}$ & $\begin{array}{l}\text { Humid } \\
\text { subtropical }\end{array}$ & RSV, influenza A, adenovirus, parainfluenza \\
\hline Mainz, Germany & $\begin{array}{l}\text { Du Prel JB et al. Clin Infect Dis } \\
2009 ; 49(6): 861-8 .\end{array}$ & Oceanic & Rhinovirus, RSV, influenza A, adenovirus \\
\hline
\end{tabular}

Table 2: the respiratory viruses that most frequently caused hospitalizations of children in temperate and tropical locations. 


\section{E2 - lab studies with viruses in aerosol chambers}

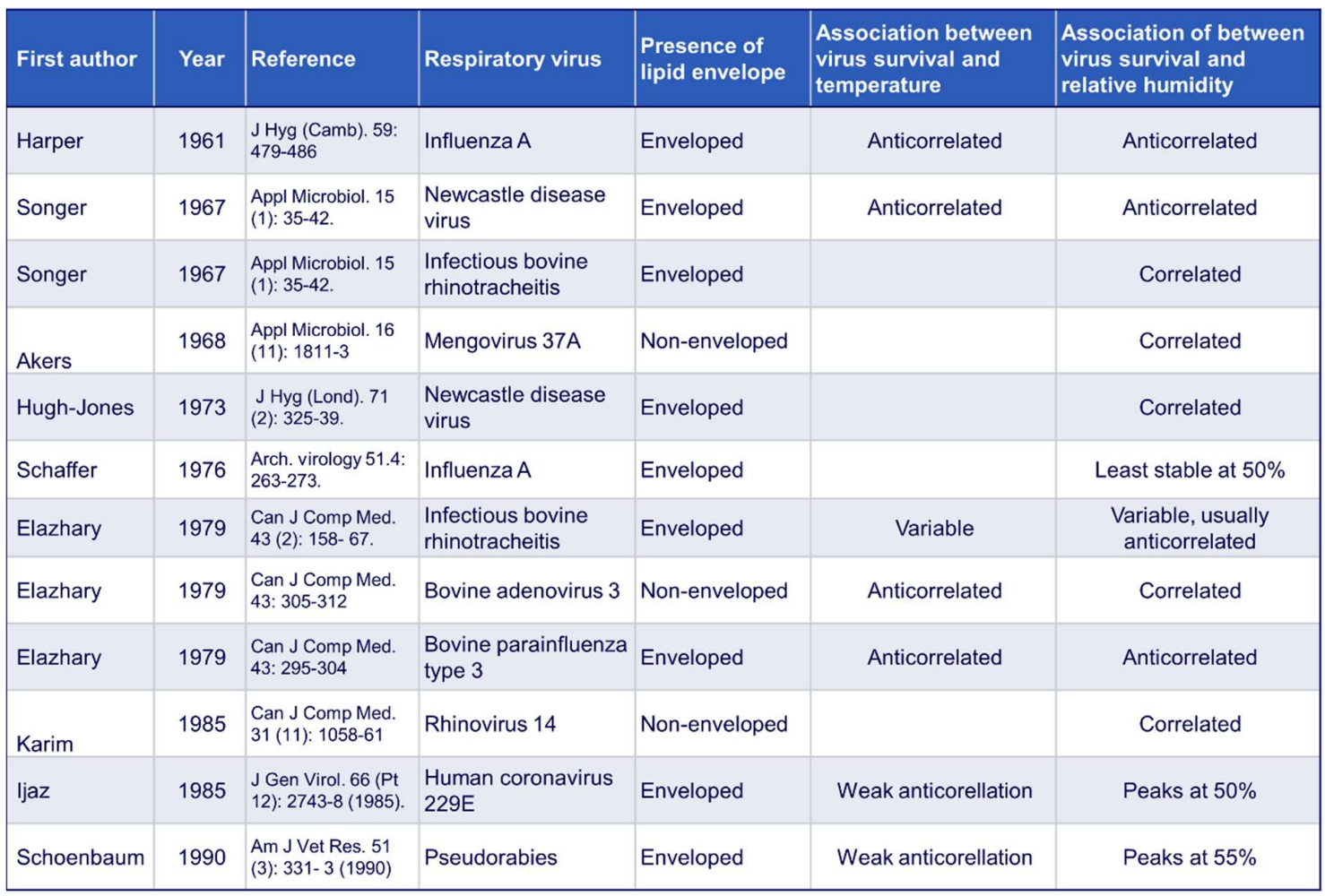

Table 3: Laboratory studies of the survival of viruses in aerosols. It has been suggested (E2) that e.g. influenza seasonality is the result of the greater stability of flu virions in cold, dry conditions [2]. In the 12 studies shown, virus aerosols were introduced into rotating drums (the rotation stops the virions from settling) and the stability of virions was measured in air of different humidities. Note that several respiratory viruses (including influenza virus) are indeed more stable in dry air, but that several others, including rhinovirus and adenovirus, are much more stable in moist air. 


\section{References}

[1] R. E. Hope-Simpson, "Epidemic mechanisms of type A influenza," Epidemiology \& Infection, vol. 83, no. 1, pp. 11-26, Aug. 1979.

[2] J. Tamerius, M. I. Nelson, S. Z. Zhou, C. Viboud, M. A. Miller, and W. J. Alonso, "Global influenza seasonality: reconciling patterns across temperate and tropical regions," Environmental health perspectives, vol. 119, no. 4, pp. 439-445, Apr. 2011.

[3] S. Hajat, W. Bird, and A. Haines, "Cold weather and GP consultations for respiratory conditions by elderly people in 16 locations in the UK," European Journal of Epidemiology, vol. 10, no. 10, pp. 959-968, 2004.

[4] S. Paynter, R. S. Ware, P. D. Sly, G. Williams, and P. Weinstein, "Seasonal immune modulation in humans: observed patters and potential environmental drivers," Journal of Infection, vol. 70, no. 1, pp. 1-10, 2015.

[5] R. E. Hope-Simpson, The transmission of epidemic influenza. Springer Science \& Business Media, 2013.

[6] P. Mecenas, R. Travassos da Rosa Moreira Bastos, A. Carlos Rosario Vallinoto, and D. Normando, "Effects of temperature and humidity on the spread of COVID-19: A systematic review," PLoS One, vol. 15, no. 9, p. e0238339, September 18, 2020.

[7] O. M. Lidwell, R. W. Morgan, and R. E. Williams, "The epidemiology of the common cold IV. The effect of weather.," Epidemiology \& Infection, vol. 63, no. 3, pp. 427-439, 1965.

[8] K. A. Kormuth et al., "Influenza virus infectivity is retained in aerosols and droplets independent of relative humidity," Journal of Infectious Diseases, vol. 2018, no. 5, pp. 739747, 2018.

[9] D. F. Milam and W. G. Smillie, "A bacteriological study of "colds" on an isolated tropical island (St. John, United States Virgin Islands, West Indies)," The Journal of Experimental Medicine, vol. 53, no. 5, pp. 733-752, 1931.

[10] C. H. Andrewes, "Adventures among viruses. III. The Puzzle of the Common Cold," Reviews of Infectious Diseases, vol. 11, no. 6, pp. 1022-1028, 1989.

[11] H. F. Dowling, G. G. Jackson, I. G. Spiesman, and T. Inouye, "Transmission of the common cold to volunteers under controlled conditions. III. The effect of chilling of the subjects upon susceptibility.," American Journal of Hygiene, vol. 68, no. 1, pp. 59-65, 1958.

[12] R. G. Douglas Jr, K. M. Lindgren, and R. B. Couch, "Exposure to cold environment and rhinovirus common cold: failure to demonstrate effect," New England Journal of Medicine, vol. 279, no. 14, pp. 742-747, 1968.

[13] E. Hyppönen and C. Power, "Hypovitaminosis D in British adults at age 45y: nationwide cohort study of dietary and lifestyle predictors," American Journal of Clinical Nutrition, vol. 85, no. 3, pp. 860-868, 2007.

[14] J. E. Manson et al., "Vitamin D Supplements and Prevention of Cancer and Cardiovascular Disease," The New England Journal of Medicine, vol. 380, pp. 33-44, 2019.

[15] R. B. Weller, "Beneficial effects of sunlight may account for the correlation between serum vitamin D levels and cardiovascular health," JAMA Cardiology, vol. 5, p. 109, 2020.

[16] J. B. du Prel et al., "Are meteorological parameters associated with acute respiratory tract infections?," Clinical infectious diseases, vol. 49, no. 6, pp. 861-868, 2009.

[17] M. Viegas, P. R. Barrero, A. F. Maffey, and A. S. Mistchenko, "Respiratory viruses' seasonality in children under five years of age in Buenos Aires, Argentina. A five year analysis," Journal of Infection, vol. 49, no. 3, pp. 222-228, 2004.

[18] F. T. Chew, S. Doraisingham, A. E. Ling, G. Kumarasinghe, and B. W. Lee, "Seasonal trends of viral respiratory tract infections in the tropics," Epidemiology \& Infection, vol. 121, no. 1, pp. 121-128, 1998.

[19] R. E. Hope-Simpson, "The role of season in the epidemiology of influenza," Epidemiology \& Infection, vol. 86, no. 1, pp. 35-47, 1981.

[20] J. J. Van Loghem, "An epidemiological contribution to the knowledge of the respiratory diseases," Epidemiology \& Infection, vol. 28, no. 1, pp. 33-54, 1928.

[21] C. J. Carlson, A. C. R. Gomez, S. Bansal, and S. J. Ryan, "Misconceptions about weather and seasonality must not misguide COVID-19 response," Nature, vol. 11, no. 4312, 2020.

[22] B. F. Zaitchik et al., "A frameworkfor research linking weather, climate and COVID-19," Nature Communications, vol. 11, no. 1, pp. 1-3, Nov. 12, 2020. 
[23] A. J. o. M. Care. (2021). A Timeline of COVID-19 Developments in 2020. Available: https://www.ajmc.com/view/a-timeline-of-covid19-developments-in-2020

[24] Y. Gu. (2021). Covid-19-Projections. Available: https://covid19-projections.com/

[25] (2021). National Climate Report. Available: https://www.ncdc.noaa.gov/sotc/national/202009

[26] S. Ansart, C. Pelat, P. Y. Boelle, F. Carrat, A. Flahault, and A. J. Valleron, "Morality burden on the 1918-1919 influenza pandemic in Europe," Influenza and other respiratory viruses, vol. 3, no. 3, pp. 99-106, 2009.

[27] A. Bendix. (2021). India's sudden drop in coronavirus cases has puzzled disease experts. Strict public health measures and difficulty recording rural cases may have factored in. Available: https://www.businessinsider.com/india-decline-coronavirus-cases-deaths-whathappened-2021-2

[28] M. Nguyen and L. Martinez. (2021). LA's COVID Cases, Deaths Decrease 'Significantly'. Available: https://laist.com/latest/post/20210201/LA-covid-cases-deaths-decreasesignificantly

[29] (Feb. 2, 2021). Weekly epidemiological update - 2 February 2021. Available: https://www.who.int/publications/m/item/weekly-epidemiological-update---2-february$\underline{2021}$

[30] D. D. Richman and B. R. Murphy, "The association of the temperature-sensitive phenotype with viral attenuation in animals and humans: implications for the development and use of live virus vaccines," Reviews of Infectious Diseases, vol. 1, no. 3, pp. 413-433, 1979.

[31] P. D. Shaw Stewart, "Seasonality and selective trends in viral acute respiratory tract infections," Medical hypotheses, vol. 1, no. 86, pp. 104-119, Jan. 2016.

[32] R. Eccles, "Why is temperature sensitivity important for the success of common respiratory viruses?," Reviews in Medical Virology, vol. 10, no. e02153, Aug. 2020.

[33] (April 1, 2020). Viral hemorragic fever. Available: https://en.wikipedia.org/wiki/Viral hemorrhagic fever

[34] C. E. Cressler, D. V. McLeod, C. Rozins, J. Van Den Hoogen, and T. Day, "The adaptive evolution of virulence: a review of theoretical predictions and empirical tests," Parasitology, vol. 143, no. 7, pp. 915-930, 2016.

[35] F. Fenner and I. D. Marshall, "A comparison of the virulence of European rabbits (Oryctolagus cuniculus) of straing of myxoma virus recovered in the field in Australia, Europe and America," Epidemiology \& Infection, vol. 55, no. 2, pp. 149-191, 1957.

[36] P. W. Ewald, "Host-parasite relations, vectors, and the evolution of disease severity," Annual Review of Ecology and Systematics, vol. 14, no. 1, pp. 465-485, 1983.

[37] D. C. Thompson et al., "The impact of COVID-19 pandemic on long-term care facilities worldwide: An overview on international issues," BioMed Research International, vol. 2020, 2020.

[38] D. A. J. Tyrrell and R. Parsons, "Some virus isolations from common colds. III. Cytopathic effects in tissue cultures," The Lancet, pp. 239-242, 1960.

[39] A. F. Bradburne, M. L. Bynoe, and D. A. J. Tyrell, "Effects of a "new" human respiratory virus in volunteers," British Medical Journal, vol. 3, no. 5568, p. 767, 1967.

[40] H. Stern and K. C. Tippett, "Primary isolation of influenza viruses at 33 degrees C," The Lancet, vol. 1, no. 7294, p. 1301, 1963.

[41] H. C. Kung, K. F. Jen, W. C. Yuan, S. F. Tien, and C. M. Chu, "Influenza in China in 1977: recurrence of influenza A subtype H1N1," Bulletin of the World Health Organization, vol. 56, no. 6, p. 913, 1987.

[42] J. S. Oxford, T. Corcoran, and G. C. Schild, "Naturally occurring temperature-sensitive influenze A viruses of the H1N1 and H3N2 subtypes," Journal of General Virology, vol. 48, no. 2, pp. 383-389, 1980.

[43] M. Jardon and A. Garnier, "PH, pCO2, and temperature effect on R-adenovirus production," Biotechnology progress, vol. 19, no. 1, pp. 202-208, 2003.

[44] K. Sato et al., "Efficient isolation of human parainfluenza viruses 1 and 3 using MNT-1, a human malignant melanoma cell line system that exhibits an apparent cytopathic effect," Microbology and immunology, vol. 60, no. 11, pp. 801-805, Nov. 2016. 
[45] K. Sato et al., "Efficient isolation of human metapneumovirus using MNT-1, a human malignant melanoma cell line with early and distinct cytopathic effects," Microbology and immunology, vol. 61, no. 11, pp. 497-506, Nov. 2017.

[46] P. H. Russell, "Newcastle disease virus and two influenza viruses: differing effects of acid and temperature on the uptake of infectious virus into bovine and canine kidney cell lines," Archives of Virology, vol. 88, no. 3-4, pp. 159-166, 1986.

[47] E. Takashita, Y. Muraki, K. Sugawara, H. Asao, H. Nishimura, and K. Suzuki, "Intrinsic temprature sensitivity of influenza $\mathrm{C}$ virus hemagglutinin-esterase fusion protein," Journal of Virology, vol. 86, no. 23, pp. 13108-13111, 2012.

[48] S. J. Plotch and R. M. Krug, "Influenze virion transcriptase: synthesis in vitro of large, polyadenylic acid-containing complementary RNA," Journal of Virology, vol. 21, no. 1, pp. 2434, 1977.

[49] A. Nagele and H. Meier-Ewert, "Influenza-C-virion-associated RNA-dependent RNA polymerase activity," Bioscience Reports, vol. 4, pp. 703-706, 1984.

[50] Y. Muraki and S. Hongo, "The molecular virology and reverse genetics of influenza C virus," Japan Journal of Infectious Diseases, vol. 63, no. 3, pp. 157-165, 2010.

[51] I. Ulmanen, B. Broni, and R. M. Krug, "Influenza virus temperature-sensitive cap (m7GpppNm)-dependent endonuclease," Journal of Virology, vol. 45, no. 1, pp. 27-35, 1983 Jan 1.

[52] C. Scholtgissek and R. Rott, "Effect of temperature on the multiplication of an influenze virus," Journal of General Virology, vol. 5, no. 2, pp. 283-290, 1969.

[53] P. Gale, "How virus size and attachment parameters affect the temperature sensitivity of virus binding to host cells: Predictions of a thermodynamic model for arboviruses and HIV," Microbial Risk Analysis, vol. 2020, no. 100104, 2020.

[54] F. Narberhaus, T. Waldminghaus, and S. Chowdhury, "RNA Thermometers," FEMS Microbiology Reviews, vol. 30, no. 1, pp. 3-16, 2006.

[55] T. Kashiwagi, K. Hara, Y. Nakazono, N. Hamada, and H. Watanabe, "Artificial hybrids of influenza A virus RNA polymerase reveal PA subunit modulates its thermal sensitivity," PLoS One, vol. 5, no. 12, p. e15140, 2010 Dec 7.

[56] R. M. Dalton, A. E. Mullin, J. J. Amorim, E. Medcalf, L. S. Tiley, and P. Digard, "Temperature sensitive influenza A virus genome replication results from low thermal stability of polymerase-cRNA complexes," Virology, vol. 3, no. 1, p. 58, 2006 Dec 1.

[57] A. Chursov, S. J. Kopetzky, I. Leshchiner, I. Kondofersky, F. J. Theis, and D. Frishman, "Specific temperature-induced perturbations of secondary nRNA structures are associated with the cold-adapted temperature-sensitive phenotype of influenza A virus," RNA Biology, vol. 9, no. 10, p. 1266, 2012.

[58] P. Massin et al., "Temperature sensitivity on growth and/or replication of H1N1, H1N2 and H3N2 influenza A viruses isolated from pigs and birds in mammalian cells," Veterinary Microbiology, vol. 142, no. 3-4, pp. 232-241, May 19, 2010.

[59] C. M. Chu, S. F. Tian, G. F. Ren, Y. M. Zhang, L. X. Zhang, and G. Q. Liu, "Occurrence of temperature-sensitive influenza A viruses in nature," Journal of Virology, vol. 41, no. 2, pp. 353-359, 1982.

[60] O. T. Preble and J. S. Youngner, "Temperature-sensitive viruses and the etiology of chronic and inapparent infections," Journal of Infectious Diseases, vol. 131, no. 4, pp. 467-473, 1975.

[61] D. W. Frielle and D. D. Huang, "Persistent infection with influenza A virus: evolution of virus mutants," Virology, vol. 138, no. 1, pp. 103-107, 1984.

[62] B. Liu, M. Hossain, I. Mori, and Y. Kimura, "Evaluation of a virus derived from MDCK cells infected persistently with influenza A virus as a potential live-attenuated vaccine candidate in the mouse model," Journal of Medical Virology, vol. 80, no. 5, pp. 888-894, 2008.

[63] R. E. Hope-Simpson and D. B. Golubev, "A new concept of the epidemic process of influenza A virus," Epidemiology \& Infection, vol. 99, no. 1, pp. 5-54, 1987.

[64] F. Gebauer, J. C. DeLaTorre, I. Gomes, M. G. Mateu, H. Barahona, and B. Tiraboschi, "Rapid selection of genetic and antigenic variants of foot-and-mouth disease virus during perisistence in cattle," Journal of Virology, vol. 62, no. 6, pp. 2041-2049, 1988.

[65] A. Lwoff, "Factors influencing the evolution of viral diseases at the cellular level and in the organism," Bacteriological Rev, vol. 23, no. 3, p. 109, 1959. 
[66] E. R. McFadden Jr. et al., "Thermal mapping of the airways in humans," Journal of Applied Physiology, vol. 58, no. 2, pp. 564-570, Feb. 1985.

[67] "Influenza virus vaccine live intranasal---Medlmmune vaccines: CAIV-T, influenza live intranasal," Drugs R.D. , vol. 4, no. 5, pp. 312-319, 2003.

[68] Y. Shachor-Meyouhas and I. Kasses, "Petechial rash with pandemic influenza (H1N1) infection," Pediatric Infectious Diseases Journal, vol. 29, no. 5, p. 480, 2010.

[69] S. Vano-Galvan and A. Martorell, "Chilblains," Canadian Medical Association Journal, vol. 184, no. 1, p. 67, Jan 102012.

[70] P. R. Massey and K. M. Jones, "Going viral: a brief history of Chilblain-like skin lesions ("COVID toes") amidst the COVID-19 pandemic," Seminars in Oncology, vol. 47, no. 5, pp. 330-334, Oct. 2020.

[71] S. S. Evans, E. A. Repasky, and F. D.T., "Fever and the thermal regulation of immunity: the immune system feels the heat," Nature Reviews Immunology, vol. 15, no. 6, pp. 335-349, June 2015.

[72] C. I. Schulman et al., "The effect of antipyretic therapy upon outcomes in critically ill patients: a randomized, prospective study," Surgical Infections, vol. 6, no. 4, pp. 369-375, Aug. 2005.

[73] M. Galanti et al., "Rates of asymptomatic respiratory virus infection across age groups," Epidemiology \& Infection, vol. 147, no. e176, pp. 1-6, 2019.

[74] M. Galanti et al., "Longitudinal active sampling for respiratory viral infections across age groups," Influenza and other respiratory viruses, vol. 13, no. 3, pp. 226-232, May 2019.

[75] J. Shaman and M. Galanti, "Direct measurement of rates of asymptomatic infection and clinical care-seeking for seasonal coronavirus," medRxiv, Jan. 1, 2020.

[76] A. Granados, E. C. Goodall, L. K. Luinstra, M. Smieja, and J. Mahony, "Comparison of asymptomatic and symptomatic rhinovirus infections in university students: incidence, species diversity, and viral load," Diagnostic Microbiology and Infectious Disease, vol. 82, no. 4, pp. 292-296, Aug. 1, 2015.

[77] B. V. Tandale et al., "Seroepidemiology of pandemic influenza A (H1N1) 2009 virus infections in Pune, India," British Medical Journal Infectious Diseases, vol. 10, no. 1, p. 255, Dec. 1, 2010.

[78] J. Papenburg et al., "Household transmission of the 2009 pandemic A/H1N1 influenza virus: elevated laboratory-confirmed secondary attack rates and evidnce of asymptomatic infections," Clinical infectious diseases, vol. 51, no. 9, pp. 1033-1041, Nov. 1, 2010.

[79] P. Q. Thai et al., "Pandemic H1N1 virus transmission and shedding dynamics in index case housholds of a prospective Vietnamese cohort," Journal of Infection, vol. 68, no. 6, pp. 581590, June 1, 2014.

[80] H. M. Foy, M. K. Cooney, I. D. Allan, and J. K. Albrecht, "Influenza B in households: virus shedding without symptoms or antibody response," American Journal of Epidemiology, vol. 126, no. 3, pp. 506-515, Sep. 1, 1987.

[81] A. S. Cameron and B. W. Moore, "The epidemiology of respiratory infection in an isolated Antarctic community," Journal of Hygiene, vol. 66, no. 3, pp. 427-437, 1968.

[82] T. R. Allen, A. F. Bradburne, E. J. Stott, C. S. Goodwin, and D. A. J. Tyrell, "An outbreak of common colds at an Antarctic base after seventeen weeks of complete isolation," Journal of Hygiene, vol. 71, no. 4, pp. 657-667, 1973.

[83] H. G. Muchmore, A. J. Parkinson, J. E. Humphries, E. N. Scott, D. A. McIntosh, and L. V. Scott, "Persistent parainfluenza virus shedding during isolation at the South Pole," Nature, vol. 289, pp. 187-189, 1981.

[84] S. Mudd and S. B. Grant, "Reactions to chilling of the body surface: experimental study of a possible mechanism for the excitation of infections of the pharynx and tonsils.," The Journal of Medical Research, vol. 40, no. 1, p. 53, May 1919.

[85] G. Donaldson, "Cold exposure and winter mortality from ischaemic heart disease, cerebrovascular disease, respiratory disease, and all causes in warm and cold regions of Europe," The Lancet, vol. 349, no. 9092, pp. 1341-1346, May 10, 1997.

[86] (2021). Coronavirus (COVID-19) Cases. Available: https://ourworldindata.org/covidcases?country=IND $U S A \sim G B R \sim C A N \sim D E U \sim F R A$ 
[87] O. Byambasuren, M. Cardona, K. Bell, J. Clark, M. L. McLaws, and P. Glasziou. (Apr. 23, 2020). Estimating the extent of true asymptomatic COVID-19 and its potential for community transmission: systematic review and meta-analysis. Available: https://papers.ssrn.com/sol3/papers.cfm?abstract id=3586675

[88] J. Pan et al., "Warmer weather unlikely to reduce the COVID-19 transmission: An ecological study in 202 locations in 8 countries," Science of the Total Environment, vol. 753, p. 142272, Jan. 2021.

[89] C. Guo et al., "Meteorological factors and COVID-19 incidence in 190 countries: an observational study," Science of the Total Environment, vol. 25, no. 757, p. 143783, Feb. 2021.

[90] M. Ward, S. Xiao, and Z. Zhang, "Humidity is a consistent climactic factor contributing to SARS-CoV-2 transmission," Transboundary and Emerging Diseases, vol. 00, pp. 1-6, 2020.

[91] S. Jamshidi, M. Baniasad, and D. Niyogi, "Global to USA county scale analysis of weather, urban density, mobility, homestay and mask use on COVID-19," International Journal of Environmental Research and Public Health, vol. 17, no. 21, 2020.

[92] T. Bedford et al., "Global circulation patterns of seasonal influenza viruses vary with antigenic drift," Nature, vol. 523, no. 7559, pp. 217-220, July 2015. 